\title{
ORNL's Envelope Stakeholder Workshop Proceedings
}

\section{Presented by Oak Ridge National Laboratory}

May 18-19, 2015

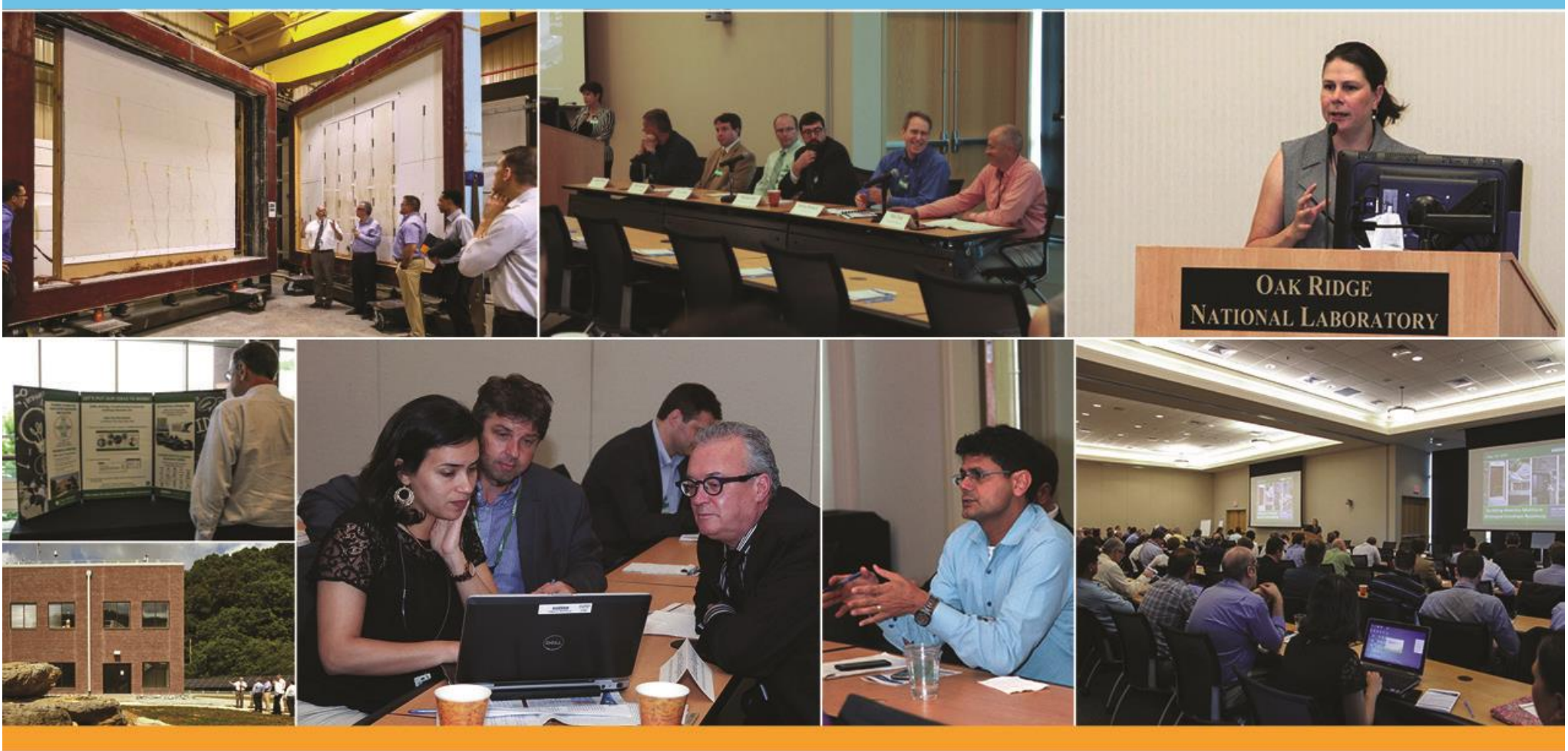




\section{DOCUMENT AVAILABILITY}

Reports produced after January 1, 1996, are generally available free via the U.S. Department of Energy (DOE) Information Bridge.

Web site http://www.osti.gov/bridge

Reports produced before January 1, 1996, may be purchased by members of the public from the following source.

National Technical Information Service

5285 Port Royal Road

Springfield, VA 22161

Telephone 703-605-6000 (1-800-553-6847)

TDD 703-487-4639

Fax 703-605-6900

E-mail info@ntis.gov

Web site http://www.ntis.gov/support/ordernowabout.htm

Reports are available to DOE employees, DOE contractors, Energy Technology Data Exchange (ETDE) representatives, and International Nuclear Information System (INIS) representatives from the following source.

Office of Scientific and Technical Information

P.O. Box 62

Oak Ridge, TN 37831

Telephone 865-576-8401

Fax 865-576-5728

E-mail reports@osti.gov

Web site http://www.osti.gov/contact.html

This report was prepared as an account of work sponsored by an agency of the United States Government. Neither the United States Government nor any agency thereof, nor any of their employees, makes any warranty, express or implied, or assumes any legal liability or responsibility for the accuracy, completeness, or usefulness of any information, apparatus, product, or process disclosed, or represents that its use would not infringe privately owned rights. Reference herein to any specific commercial product, process, or service by trade name, trademark, manufacturer, or otherwise, does not necessarily constitute or imply its endorsement, recommendation, or favoring by the United States Government or any agency thereof. The views and opinions of authors expressed herein do not necessarily state or reflect those of the United States Government or any agency thereof. 


\section{Disclaimer}

All information, materials or services furnished under or with this report are provided on an "as is" basis. Neither UT-Battelle, LLC, DOE, nor persons acting on their behalf make any representations or extend any warranties, either express or implied, (a) with respect to the validity of the information contained in the deliverables; (b) with respect to the merchantability, accuracy, completeness, fitness for use, or usefulness of any deliverables; (c) that the use of any such deliverables will not infringe upon privately owned rights; (d) that the deliverables will not result in injury or damage when used for any purpose; (e) that the deliverables will accomplish the intended results or are safe for any purpose, including the intended or particular purpose. It is agreed that neither UT-Battelle, LLC, nor DOE will be liable for consequential, special, or incidental damages caused by or related to the use of the deliverables. Neither UT-Battelle, LLC, nor DOE has independently verified the information included in the deliverables, and statements contained therein should not be viewed as an endorsement of any product or service by UTBattelle, LLC, or DOE. 

Energy and Transportation Science Division

ORNL's Envelope Stakeholder Workshop Proceedings

Melissa Lapsa, Oak Ridge National Laboratory

Tyler Grubbs, SRA International

Gannate Khowailed, SRA International

September 2015

Prepared by

OAK RIDGE NATIONAL LABORATORY

Oak Ridge, Tennessee 37831-6283

managed by

UT-BATTELLE, LLC

for the

U.S. DEPARTMENT OF ENERGY

under contract DE-AC05-00OR22725 



\section{TABLE OF CONTENTS}

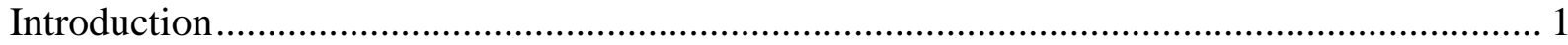

Welcome: Eric Werling, DOE BTO, and Amy Jiron, DOE BTO ……….............................. 2

Keynote Speaker: Joseph Lstiburek, Building Science Corporation ............................................ 3

ORNL Buildings Crowdsourcing Community Update............................................................ 6

Fireside Chat with Building Owners/Managers-Leslie Nichols, Moderator.............................. 6

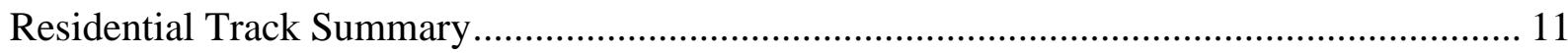

DETAILED MINUTES OF THE RESIDENTIAL TRACK............................................... 14

Commercial Track Breakout Session: Windows and Shading, Michelle Coates, Moderator .. 23

Sneh Kumar, Alcoa/Kawneer "Design and Production Engineering of Highly Insulating (R5) Commercial Windows"

Helen Sanders, SAGE Electrochromics, Inc. "EC Glass for Next Generation of Sustainable Buildings" 24

John Crowley, Vice President, Rollease "Attached Energy Rating Council Program Update"

Commercial Track Breakout Session: New Envelope Technologies 26

Andre Desjarlais, ORNL (on behalf of Doug Smith), Nanopore "Modified Atmosphere Insulation-Next Generation Insulation Material".

John Letts, Firestone "Polyiso-Encapsulated MAI (Modified Atmospheric Insulation) Panels". 31

John Breshears, Architectural Applications “Airflow Panels"............................................... 33

Shawn Prestegaard, 3M "Air Barrier Technologies that Challenge the Status Quo"........... 34

Lunch Speaker: Nicholas Holt, Skidmore, Owings, and Merrill (SOM) "A Return to Performance"

Commercial Track Breakout Session: Envelope Retrofit Applications, Diana Hun, Moderator

Steve Debusk, Eastman Chemical "Retrofit EnerLogic Low-e Window Films" 38

Craig Tyler, Carlisle Construction Materials "Roof Tie-ins: New Roofs with Existing Air and Vapor Barriers"

Amy Wylie, Bayer Material Science, "Packaged Masonry Wall Retrofit Solutions for Small and Medium-size Commercial Buildings"....

Commercial Track Breakout Session: Air Barriers 
Katherine Faber, The Dow Chemical Company "One-Step Sprayable Liquid Flashing Technology to Increase Energy Savings and Decrease Installation Time" ....................... 43

Marysusan Couturier, WR Grace "Energy Savings with Fully-Adhered Weather Barrier" .... 45

Marcy Tyler, Tremco, Inc. "Air Barrier Technology with Extreme Performance in Extreme

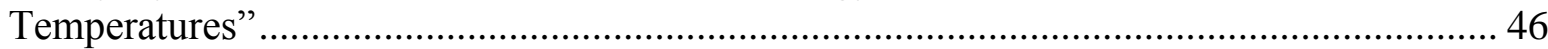

Commercial Track Moderator Highlights....................................................................... 48

New Envelope Technologies ............................................................................... 48

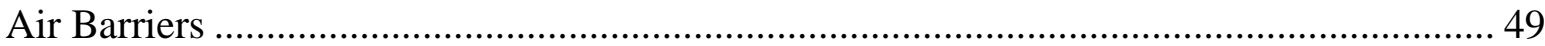

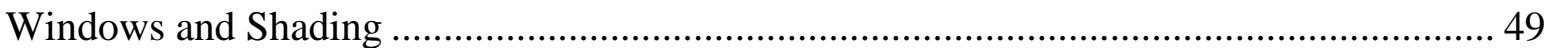

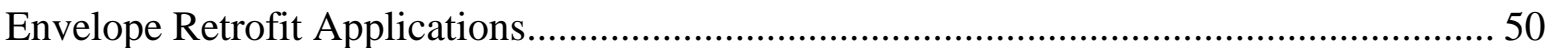

Residential and Commercial Crosscutting ........................................................................ 51

Mike Ennis, SPRI, "Code and Green Building Design Guide Requirements and Their Impact

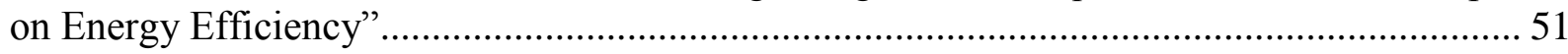

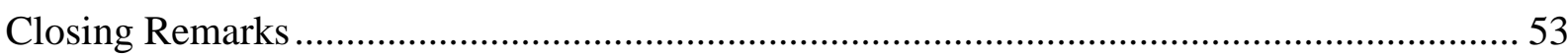

Doug Brookman, "Report out from Residential Sessions" ........................................... 53

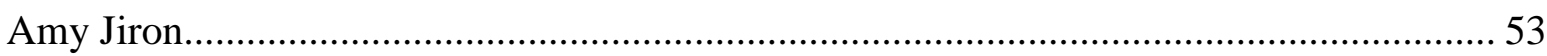

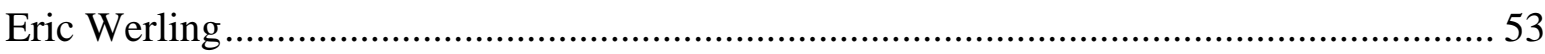

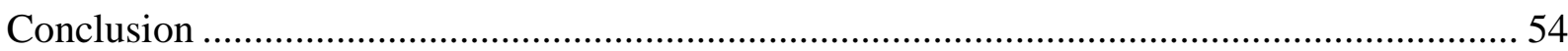

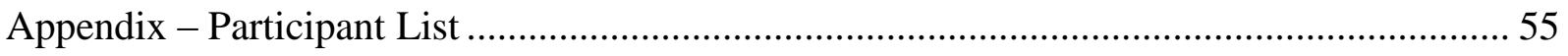




\section{INTRODUCTION}

The 2015 Building Envelope Stakeholder Workshop hosted by Oak Ridge National Laboratory (ORNL) brought together representatives from diverse public and private entities. Presenters included senior Department of Energy (DOE) officials, ORNL personnel, and a myriad of corporate partners. To promote the use of energy-efficient technologies in commercial and residential buildings, the following issues were discussed:

- Identifying current and anticipated barriers to the adoption of energy-efficient commercial envelope technologies

- Reviewing emerging and market-ready applications for new and existing commercial buildings

- Defining a path forward for commercial envelope products

- Discussing and soliciting feedback on DOE's strategic research road map for highperformance, moisture-managed envelope solutions for residential buildings

This summary report describes key findings derived from these discussions as well as a distillation of the many discussions that unfolded during the event. It is hoped that it will be used not only to transmit this information to interested parties but also, more important, to foster continuing discussion and encourage input useful in furthering the broader goals of fostering the adoption of energy-efficient building technologies across various markets. 
Eric Werling directs the DOE Building America program with a diverse program portfolio of whole-house energy efficiency research and demonstration projects, including industry partner teams and DOE national labs. Before coming to DOE, he launched the US Environmental Protection Agency's (EPA) Indoor airPLUS home labeling program in 2009. He also funded and oversaw development of ASHRAE's popular Indoor Air Quality Guide, EPA's Healthy Indoor Environment Protocols for Home Energy Upgrades, and EPA's Moisture Control Guidance for Building Design, Construction and Maintenance. From 1995 to 2004, at ICF Consulting, Eric helped EPA build the successful ENERGY STAR for New Homes program and managed the New York ENERGY STAR Homes program. Eric is a voting member of SSPC 62.2, serves on the ASHRAE IAQ 2016 Steering Committee, and has been an ASHRAE member since 1995. He holds a master's degree in architectural engineering and an MBA from Pennsylvania State University. He served in the US Navy and earned a bachelor's degree from the US Naval Academy.

Mr. Werling's presentation discussed the Building America Moisture-Managed Envelope Roadmap. Framing the scope and significance of the day's events, he transitioned to a graph illustrating that US residential buildings' primary energy consumption stands at 22 quad, with field-assembled comfort systems (envelope and heating, ventilation, and air-conditioning [HVAC]) accounting for $43 \%$ of that figure. In the decade 2010-2020, the Building America Roadmap will seek to address three interrelated challenges: high-performance thermal enclosures, smart ventilation and indoor air quality, and low-load efficient HVAC. He stressed that energy codes lag behind market growth, which in turn follows proven high-performance home solutions. That is to say, innovative solutions are demonstrated by industry, after which the market realizes the value of such improvements and begins to demand them, while building codes trail behind. Research yields marketable goods, which eventually become standard practices. By 2025, DOE aims to see energy consumption as of 2012 halved. This achievement will require more insulation and tighter construction. More robust moisture resistance must be realized, as increased insulation and airtightness can elevate the risk of condensation and substantially limit the drying potential inside building assemblies. In tandem, reduced airflow and improved indoor relative humidity $(\mathrm{RH})$ are needed, since lower loads reduce air flow, increase the relative latent load, and extend swing seasons. Improved airtightness demands improved source control, dilution, and filtration. If these performance requisites are not met, high-efficiency homes will have comfort and durability problems, builders will not go further than the current codes, and future energy code improvements will advance at suboptimal rates.

Equally important are energy-efficient new and existing homes with moisture-managed, high$\mathrm{R}$-value envelopes capable of improved resistance to moisture penetration, as well as optimized low-load comfort solutions that effectively manage airflow and indoor RH for comfort. Finally, fully harnessing such technologies calls for intelligent indoor air quality solutions that control fresh air supply and contaminant removal.

The objectives of the integrated roadmaps include codes and standard practices as end points, risk management to minimize problems of adoption, addressing optimal performance and cost effectiveness, and identifying solutions that are practical and profitable for builders and home 
improvement contractors. The model for achievement is threefold: research and development, market engagement, and the judicious use of codes and standards.

Mr. Werling was followed by Amy Jiron, who manages the High Impact Technology (HIT) Catalyst program with the Commercial Buildings Integration team at DOE. The HIT Catalyst program accelerates cost-effective, voluntary high-impact technologies into the commercial buildings market based on strategic analysis of commercial buildings markets and technologies. Key to the catalyst program is the development of a cohesive step-by-step market stimulation strategy that enables DOE to leverage work by others; address stakeholder needs; integrate work into existing stakeholder networks, including the Better Buildings Program; and strategically partner with other organizations to create quantifiable energy savings impacts. Before her work with DOE, Amy served as the executive director of the US Green Building Council Colorado Chapter; advocated for low-impact development with the National Resources Defense Council; and evaluated, commissioned, and verified high-performance building design and retrofit strategies as an architectural engineer. Ms. Jiron received her Juris Doctor from the Washington College of Law in Washington, D.C., and earned a BS degree in architectural engineering from the University of Colorado in Boulder.

Ms. Jiron detailed how her work in the commercial domain complements Mr. Werling's residential focus within the context of the overall DOE Building Technologies Office (BTO) mission. She gave a brief overview of the "Tech to Market" process by which public and private partners collaborate to efficiently deliver energy-efficiency innovations to consumers, some of the obstacles to doing so, and various partners assisting in those efforts. She asked audience members for assistance in overcoming the hurdles as the day's events progress.

Highlighting a recent BTO success, Ms. Jiron detailed the issuing of a rooftop challenge intended to deliver better efficiency in rooftop cooling units. The initiative was a great success, as the number of rooftop cooling unit models exceeding 18 SEER (integrated energy-efficiency ratio) grew from zero to 21 in only a few years. She said she would like to witness the same sort of success in envelope technology adoption and exhorted attendees to share their thoughts to realize that goal.

\section{KEYNOTE SPEAKER: JOSEPH LSTIBUREK, BUILDING SCIENCE CORPORATION}

Mr. Lstiburek is a principal of Building Science Corporation and an adjunct professor of building science at the University of Toronto. He is a building scientist who investigates building failures and is internationally recognized as an authority on moisture-related building problems and indoor air quality. He is a noted authority on energy-efficient construction techniques and heads one of the four Building America program teams for DOE. He is a former director of research of the Housing and Urban Development Association of Canada, has written numerous books and technical papers on building construction, and has conducted forensic investigations and served as an expert witness on building failures all over the United States. Mr. Lstiburek is an expert in rain penetration, air barriers, vapor barriers, air quality, durability, and construction technology. 
He holds an undergraduate degree in mechanical engineering, a master's degree in civil engineering, and a PhD in building science, all from the University of Toronto. He has been a licensed professional engineer since 1982.

Mr. Lstiburek began by translating the technical concept of environmental separation in buildings into layman's terms with the metaphor of a building as an environmental separator. This separator features four interconnected components: the water-control layer, the air-control layer, the vapor-control layer, and the thermal-control layer. The first is the most critical. He noted that rotating and inverting the concept of the "perfect wall" yields the "perfect ceiling." This science was settled decades ago; it is well established and understood at a theoretical level. Implementation - i.e., developing appropriate products, delivering them to market, and installing them correctly — is the residual challenge.

The true challenge in execution exists in handling the 3-dimensional intersections of the four control layers. These interfaces complicate the work of architects, engineers, contractors, and manufacturers. As it is, manufacturers bear the burden of resolving such difficulties and are relied upon to do so consistently. Residential and commercial stakeholders face the same issues. Fortunately, adequate current technology exists and is effective.

Manufacturers rely upon models and mock-ups for simulation testing of products; while this process has been a mainstay in the commercial world for years, it is now slowly being adopted on the residential side. This adoption demonstrates well the merging of those two formerly separated domains at the project level. It can be seen in the case of dedicating a building's first floor to commercial space while several higher floors serve residential customers, both of which uses must be effectively integrated. This practice is where technology is heading, and modular, interchangeable solutions are needed. As well, wood now features more prominently in commercial applications, with steel making similar inroads into residential projects. The lines between these worlds grow less pronounced with each passing year.

Sorely needed are innovations addressing penetrations for windows and doors; joint technology is what matters. Equally pressing is the method of dealing with joints. The industry hasn't yet settled on a primary joining technology — will it be a membrane, a liquid application, or a hybrid? Similarly, adding wall materials to roofing materials has become a formalized path of innovation and integration.

Many of these innovations cannot be demonstrated theoretically, as calculation tools are still unreliable and generally not precise or comprehensive enough in their inputs. Therefore, prototyping is relied upon extensively. The challenge of hydrothermal movement between insulation batts or panels illustrates this point. There were questions about the ideal nature of insulation gaps. What kind of a gap should exist between which layers? How can we solve the issues? Physical models were constructed and comprehensively stressed. The results indicated that gaps are a necessity, although they need not be significant. Similar findings suggested that oriented strand board is the material of the future, rather than plywood. Industry innovations to address gap issues are still needed.

Iterative modeling is the path forward: building, testing, improving based on the results, and testing again. The confluence of residential and commercial construction-both sectors now use 
the same practices - is an undeniable and continuing trend. For example, flange systems are familiar residentially but not commercially. However, flanged windows, penetrations, and the like will also be used in the commercial world, as they are easier to waterproof. This is just one example among many. The issues are joints, penetrations, all sorts of materials and practices working in all construction sectors, and the general interplay between residential and commercial construction. The physics is 50 years old, but the construction industry is just now working out technical implementations and solutions. 


\section{ORNL BUILDINGS CROWDSOURCING COMMUNITY UPDATE}

Melissa Lapsa of ORNL discussed ORNL's crowdsourcing website and campaign, beginning with the three distinct campaigns: equipment and appliances, sensors and controls, and envelope technologies. Users of the site may submit their innovative ideas for new products/solutions in those categories and vote on existing submissions, with the most popular ideas going to a panel of technical experts for review. Submitters of the best ideas will then have a chance to present them at an ORNL Industry Day in September. The opportunity will include possibly having their ideas brought to life using the ORNL's 3D printing capabilities. This campaign is part of ORNL's continued commitment to facilitating innovation and faster technology-to-market processes, as well as generally fostering collaboration between the lab and industry. Attendees were encouraged to visit and given some basic statistics: the website has 300 registered users and 60 ideas, and small businesses represent $60 \%$ of the user base.

\section{FIRESIDE CHAT WITH BUILDING OWNERS/MANAGERS—LESLIE NICHOLS, MODERATOR}

Leslie Nichols of Energetics moderated a fireside chat with a panel of building owners and managers. The theme of the discussion was addressing the barriers to adoption of nextgeneration window and envelope technologies. The discussion included the following panel members.

\section{Michael Fenner, Technical Lead Specialist, Target Property Management}

Mr. Fenner started his career working in the construction industry as a roofing laborer while attending college. He spent more than 22 years working for several roofing manufacturers, including Firestone Building Products and GenFlex Roofing Systems. He has held various technical and contractor service positions and has been involved with roof inspection, warranty service, contractor training, product testing, and development. He joined Target Corporation in 2004 as a field project manager responsible for internal field roofing operations, was promoted to national roofing manager/property development in 2007, and is currently the technical lead specialist for Target Property Management. He is responsible for program management for building exterior life-cycle for all Target properties. Michael is a member of The Roof Consultants Institute. He attended Western Michigan University.

\section{Zane Foraker, Knox County Schools}

Mr. Foraker is an East Tennessee native and a 1996 graduate of the University of TennesseeKnoxville with a degree in engineering science. He is a professional engineer and a certified energy manager who spent nearly 10 years working with small energy services companies in the Knoxville area before becoming energy manager for Knox County Schools. As the first energy manager, he built an energy management program from the ground up that has reduced energy consumption in the schools by $35 \%$ since 2007 . Mr. Foraker has managed more than $\$ 70$ million in energy-saving performance contract construction for Knox County schools and will soon be installing $\$ 9$ million worth of solar panels on 11 school roofs. 


\section{Mike Ford, Garland Company, (Knoxville BOMA President)}

Since 2000, Mr. Ford has been a technical representative for Garland, a firm that specializes in exterior building envelope maintenance, waterproofing, and manufacturing. He has worked with the Y-12 National Security Complex, ORNL, Tennessee Valley Authority, Knoxville Utilities Board, McGhee Tyson Airport-Knoxville and other similar facilities. Mr. Ford is currently on the board of the Tennessee School Plant Managers Association and is the president of the Building Owners and Managers Association (BOMA) for the Greater Knoxville area

\section{Nicholas Holt, Skidmore, Owings \& Merrill, LLP}

Mr. Holt is a technical director at Skidmore, Owings \& Merrill (SOM) and approaches design by integrating building systems, sustainable design principles, and extensive construction knowledge from the conceptual development of a project through construction documentation and execution. Directing the technical architecture team in SOM's New York office, Nicholas oversees the detailed development and documentation for all of the New York office's projects. Since joining SOM in 1995, he has developed extensive experience working on high-rise and super-tall commercial and mixed-use towers, financial trading facilities, health science projects, and residential and hotel towers. With experience on numerous overseas projects, he has developed an acute understanding of working collaboratively with local owners, fabricators, and stakeholders to leverage regional conditions to meet international quality and performance standards.

\section{Terry Morton, BarberMcMurry architects}

Mr. Morton directs the construction-phase services for all projects designed by BarberMcMurry architects. His experience enables him to meet the construction needs of the firm's clients. He works in conjunction with the firm's partners, project managers, and consultants to ensure that what is designed and specified is appropriately reflected in the finished building product. He is a licensed architect and a licensed general contractor. He has worked on a diverse range of projects from higher education and churches to healthcare and industrial facilities. He has been with BarberMcMurry for 19 years. He earned a bachelor of architecture degree from the University of Arkansas and is a licensed architect in Missouri and Tennessee.

\section{Stefan Wankerl, U.S. Cellular}

Mr. Wankerl has been with U.S. Cellular since 2007 and serves as the East Region facilities specialist $\mathrm{He}$ is also the East Tennessee chapter president of the International Facility Managers Association (IFMA).

Ms. Nichols asked Mr. Fenner to share Target's approach to making the business case for projects leveraging innovative energy-efficient envelope technologies.

Mr. Fenner mentioned key factors of return on investment (ROI) over short and long horizons. Money must be spent wisely to create profit for shareholders. A secondary consideration is determining any impacts on the community and guests. Finally, any implementations must demonstrate an actual reduction in energy load.

Mr. Foraker was queried as to how the Knox County School District positions projects for approval. 
Mr. Foraker first stressed that a unique set of criteria apply to a public agency. Short-term ROI is not a factor, especially considering the 70+ year lifetimes of school buildings. As a result of these long horizons, durability is a primary concern during the construction phase. He pointed out that the things that are changed and upgraded over a building's lifetime-lights, HVAC systems, and controls - are all inside the envelope. When working with public groups, it is important to communicate that the building will be in use for decades, and investments in efficiency must be made at the time so that savings can be maximized over future generations.

Mr. Morton was asked, as an architect and contractor, how he works with customers to implement envelope energy efficiency.

Mr. Morton said many clients arrive wanting to use better practices than were the custom in the past. Many ask for LEED (Leadership in Energy and Environmental Design) building specifications without formal certification. Clients seem to be drawn as well to the aesthetics of green buildings. Sometimes they want their buildings to have a unique look, and this offers an opportunity for sun-shading and other novel solutions. More sophisticated clients understand the logic behind tighter envelopes and energy conservation generally, but even unsophisticated clients understand that building leaks are generally not hallmarks of a quality building.

Ms. Nichols asked Mr. Holt how he sells the incorporation of new and cutting-edge technology, aside from operational expense reductions.

Mr. Holt stated that, in many cases, energy cost savings are not a primary concern, as energy costs are passed on to the client. He sells by not selling at all; regulatory bodies do the selling for him. In New York, a host of green codes have elevated performance mandates. Regulatory factors drive demand by compelling the adoption of new technology. This factor, compared with all others, has advanced the most considerably in the past decade. Recruiting has changed expectations as well. College graduates are familiar with LEED building standards and want to work and live in such spaces. Incentives have changed-zoning bodies now permit the expanded use of space for profitable ends if certain envelope improvements are implemented. In many cases, this permits an additional top floor - the choicest and most expensive real estate. Such incentives are revolutionary in how clients, tenants, and users view their world. He mentioned that he often works with clients on visibility and marketing issues, and that some of the more innovative projects are done as demonstrations, allowing clients to be seen as forward-thinking thought leaders.

To Mr. Wankerl, Ms. Nichols directed a question concerning the key factors to be considered before deep-retrofit projects affecting the envelope.

Mr. Wankerl said he considers what can change and yet be maintainable, ready for expansion. He wants to save energy, but reliability is the highest priority.

Mr. Ford was asked his opinion on the easiest and hardest selling proposition in building retrofit projects.

Mr. Ford said truly educated owners readily see the value in such projects, while those who mistakenly think themselves cognizant of their needs present a challenge. Owners are reluctant to make major envelope changes because of the significance of such undertakings. Educating 
owners on the breadth of options is an important process. Helpful above all else is demonstrating to stakeholders the value of self-education. Customers often fail to see the value of a comprehensive and consultative approach to evaluating solutions. They do not hire an architect, accept the lowest bid, and proceed quickly-a process far from ideal.

Following the individually targeted questions, Ms. Nichols began a lightning round in which a prompt was directed at the panel generally, with each participant encouraged to offer a summary response. The first question: What is the biggest challenge that must be addressed before a building technology can achieve mass adoption?

Mr. Fenner: We must educate and deliver relevant information to end-users.

Mr. Foraker: Schools, as publicly-funded entities, want to be seen as spending wisely.

Mr. Morton: Lack of training in construction using new technology, along with inadequate training of the people who actually do the work, is an impediment.

Mr. Holt: Cost is the supreme concern, and those thresholds must be made more attractive to owners.

Mr. Wankerl: Project budgets are the limiting factor. There are constant pressures on the budget; reducing the expenses of a technology and its implementation will catalyze adoption.

Mr. Ford: Education, and selling the value of longevity in buildings and building systems.

Ms. Nichols asked the panel which single envelope technology or activity they would invest in.

Mr. Fenner: Policy making, codes, and consistent enforcement of codes and policies headline my list. I would add understanding the distinction between what we must do and what we need to do.

Mr. Foraker: The value of daylight in education has been proved. There is a desire to maximize natural light but a fear of leaks, which such improvements are perceived to entail. Strengthening products and backing them with solid warranties is important.

Mr. Morton: Education and training - the training of architects, contractors, and materials suppliers with mock-ups demonstrates the value of education.

Mr. Holt: Transforming market perceptions and developing the market's desire for transparency would be of much value. For example, $40 \%$ glazing works, yet customers demand $70 \%$.

Mr. Wankerl: I would invest in training on and with new technologies and in maintenance.

Mr. Ford: I would invest in the education of architects, owners, and end users - understanding that products will be installed by the lowest-compensated worker in a company. Communication and instructions to this end must be simplified.

The group's insights were solicited regarding how trade groups can foster wider adoption of technology. 
Mr. Ford: BOMA is an organization for facility managers, vendors, and so on to network. Professionals get to network with other facility professionals and have a network of people with whom to resolve issues collaboratively.

Mr. Wankerl: IFMA offers networking and training, including expert guests.

A question from the audience: Are you seeing more commissioning requirements on code changes?

Mr. Holt: Getting codes implemented is a political exercise not driven by architects or engineers.

Mr. Foraker: Builders are responsible for building to code, but in some communities there is no staff to ensure compliance. The personnel are not there, and this leads to perverse incentives.

An audience member asked how testing conditions can be made more realistic so as to refine the current understanding of materials.

Mr. Fenner: ASTM standards are minimum standards. As owners, designers, and architects we should demand higher standards. We should be developing building design specifications and requesting from vendors more than just meeting minimum standards.

Mr. Wankerl: By specifying performance criteria based on research rather than relying on ASTM. Environmental conditions within simulations must be more varied and realistic and drive testing and design requirements. The safety factor depends on the end use - is the building in question a small warehouse or a Federal Emergency Management Agency gymnasium?

Ms. Nichols asked participants to separate into two groups: residential and commercial. Manufacturers will discuss benefits, market conditions, market uptake, and current real and perceived barriers. Ideas about meeting those points of resistance will then be solicited and discussed as a group. 


\section{RESIDENTIAL TRACK SUMMARY}

Despite significant advancement of energy efficient home technologies and best practices, including voluntary market advances and adoption of advanced codes, large technology and information gaps remain. These gaps prevent further advancement and mainstream adoption of the high-performance home technologies and systems for both new and existing homes that are needed to achieve DOE's energy-savings goals at scale.

The same market barriers that have discouraged the industry from investing in research have also led to gaps in market adoption. Increased energy performance brings new technical challenges and can increase risk to builders and contractors. Real and perceived risks associated with adopting new technologies, combined with a general lack of understanding by housing industry stakeholders of business models that can create profit from improved home performance, prevent quick uptake of new energy-saving technologies and design approaches. Without proof that these new technologies and business models are safe, effective, and provide real business benefits, the market will not move forward with energy efficiency at the rate required to meet DOE's longterm energy-savings goals.

Today's building envelope assemblies are less tolerant of design and installation flaws. Modern building envelopes do not dry out as easily as old, inefficient structures which inherently increase the risks of moisture accumulation within building assemblies. Before any further advancement of building energy codes (e.g., additional insulation or air-sealing requirements) is possible, these envelope moisture risks must be better managed.

To solve these problems and help the housing industry and building codes improve home performance and reach aggressive efficiency goals, Building America has developed a new program strategy. Leveraging past Building America successes and lessons learned, DOE has identified critical research and information gaps for three key housing technology areas, represented in a new Building America Research-to-Market Plan and three Technology-toMarket Roadmaps: High Performance Moisture Managed Envelope Solutions; Optimal Comfort Systems for Low-Load Homes; and Optimal Ventilation \& IAQ Solutions. This Plan and associated Roadmaps will be published by DOE in early fall 2015.

As part of the development of the Plan, the Building America Technology-to-Market Roadmaps were circulated to industry experts for their review and comments. The purpose of the Residential Track session - which is the subject of this report - was to focus on the High Performance Moisture Managed Envelope Solutions Roadmap, to discuss comments received during the review and to finalize the Roadmap for the published Plan.

The Building America Research-to-Market Plan will be revised in coming years to reflect continuous stakeholder input, and to address incremental progress toward RD\&D goals laid out in the Roadmaps. 
Proposed activities associated with the High Performance Moisture Managed Envelope Solutions Roadmap are depicted in the following Gantt chart.

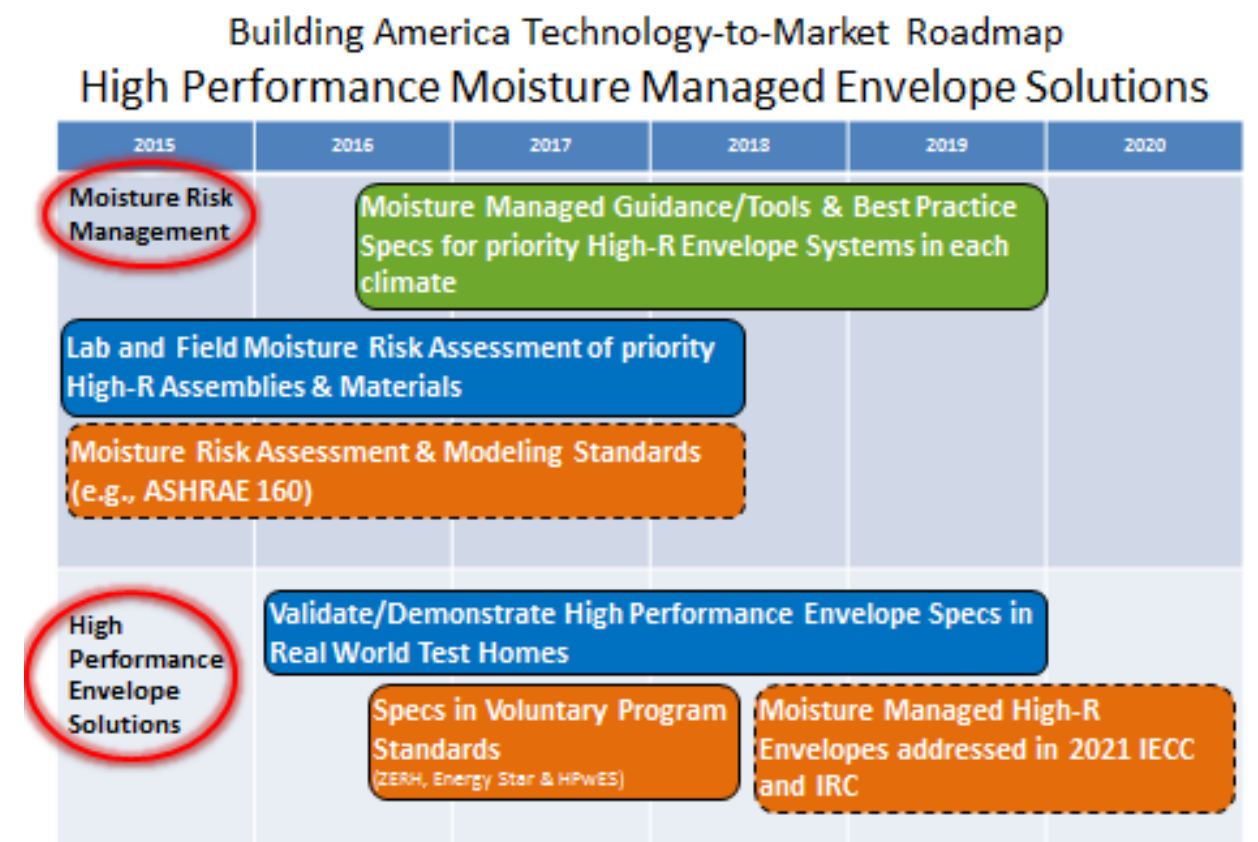

Figure 1: High-Performance Moisture-Managed Envelope Solutions Roadmap Gantt Chart

A diverse group consisting of 19 representatives from industry, four from DOE, and seven from national laboratories was asked to help enhance the upcoming Building America Roadmap on building envelopes. Feedback was requested on the overall structure of BA's upcoming roadmap and its various elements. Also, a remaining set of comments solicited through a DOE request for information were addressed with the help of participants. A separate document has been prepared and submitted to Building America capturing the highlighted discussion topics in detail.

Morning Session: The session kicked off with moderator Doug Brookman posing the following high-level questions for discussion:

- What does success look like for building energy efficiency and durability if DOE stakeholders should be tremendously successful?

$>$ A need was expressed for market-ready solutions that are both easily installed and cost-effective. To achieve this, better metrics/guidance for product forgiveness for handling risk is necessary. In other words, you can build a perfect wall, but a perfect wall is likely not cost-effective, so what can pass as sufficient? Risk is strongly affected by the load, in this case defined as the interior and exterior movements of water. More information is needed on interior boundary conditions (e.g., set point temperature and relative humidity), so participants suggested conducting a survey or leveraging existing data (e.g., Google NEST Learning Thermostat) to capture the missing data. 
- What new or emerging technologies will evolve for moisture management solutions in buildings, and how might these impact the shape of the roadmap?

$>$ Attendees concluded that it may be useful to have output from studies but not frame a section of a roadmap around the development of any one emerging technology until it has established a sizeable market share.

The morning was closed out by participants helping BTO to address remaining comments from a recent request for information, broken down into the following five categories:

1. Materials Properties Development

2. Field Testing of Assemblies

3. Fenestration

4. Codes

5. Other Roadmap Issues

Afternoon Session: Participants were asked to review a list of wall systems and judge risk in terms of implementation and technology challenge for both cold and hot-humid climates. For cold climates, the greatest risk was determined to be condensation associated with increased insulation. For certain assemblies, moving to heavier cladding could also cause problems with finding the stud, potentially resulting in an envelope breach. Energy codes were also raised as a major concern, as participants believed there is an educational gap in technology transfer to the builder. Builders are aware that the current code sometimes results in failures where there are increased levels of insulation. The more support and better the guidance provided to the building community, the more likely they are to accept future code changes. For hot-humid climates, participants agreed that the wall systems of interest work relatively well and most risks are well understood.

Similar questions were asked about foundations and attics in the two climates. Again, codes lack proper guidance for mitigating air leakage, vapor leakage, and duct leakage in sealed, semiconditioned attics, presenting challenges to properly sealing and controlling moisture movement. Specific to hot-humid climates, increased risks were related to equipment failing more quickly and vapor accumulating in the permeable insulation sheathing overnight (i.e., the ping pong effect). For foundations, participants agreed that 9 out of 10 moisture problems occur because of poor or incorrect backfilling, which is an implementation issue. For hot-humid climates, foundations are a lesser issue because concrete slabs are more common than traditional crawlspaces.

During the wrap-up, participants were asked for input on supplementary information sources that may provide continued support and guidance to the roadmap work. Responses included the following work, initiatives, and/or upcoming events from the US Environmental Protection Agency, American Chemical Council, California Energy Commission, Natural Resources Canada, National Research Council Canada, ASTM, PROSOCO, the Spray Foam Coalition, the International Energy Agency's Energy Conservation in Buildings and Community Systems, and the upcoming Thermal Performance of the Exterior Envelopes of Whole Buildings XIII International Conference in 2016. 
Mr. Brookman also asked participants what they viewed as keys to a successful implementation of the roadmap by DOE. As in early sessions, most feedback was associated with making improvements to code that provide better guidance to builders, particularly with regard to moisture issues. Participants also felt that the most important goal of the roadmap is proper handoff to the market, i.e., the final deliverable should not be a report but instead a metric that the end users can rely on (e.g., Energy Score). Builders are nervous about upcoming changes related to airtightness and ventilation, and they want/need proper guidance and good information.

\section{DETAILED MINUTES OF THE RESIDENTIAL TRACK}

The Buildings Technology Research Integration Center (BTRIC) of the Oak Ridge National Laboratory (ORNL) invited building industry representatives, National Labs and the DOE to participate and collaborate on building envelope directives for walls, roofs, attics and foundations. Goal is to setup stronger partnerships and new programs geared to navigate the changing energy efficiency challenges for net zero buildings. Attendees chose between the commercial and residential sectors and participated in discussions to set or revise priority areas of policy. Comments were solicited and encouraged on each topic area. The following is a synopsis of the discussions presented at the residential breakout session.

The residential breakout session participants were given the opportunity to provide significant feedback on BA's Roadmap and its various elements. Also, DOE solicited many comments through an RFI and have distilled comments down to approximately 20 remaining comments. Participants helped to address these remaining questions.

Attendees to Residential Sector (19 industry participants)

\begin{tabular}{|l|l|}
\hline Jay Crandell & ARES Consulting \\
\hline Richard Duncan & Spray Foam Alliance \\
\hline Diana Fisher & Johns Manville \\
\hline Andrew Frye & TVA \\
\hline Samuel Glass & USDA Forest Products \\
\hline Dianne Griffiths & Steven Winters Associates \\
\hline Anthony Grisolia & IBACOS \\
\hline Patrick Huelman & University of Minnesota \\
\hline Achilles Karagiozis & Owens Corning \\
\hline Jim Lambach & Bayer MaterialScience \\
\hline
\end{tabular}




\begin{tabular}{|l|l|}
\hline Joseph Lstiburek & Building Science Corporation \\
\hline Jean-Philippe Ndobo-Epoy & CertainTeed \\
\hline Dave Pennington & PROSOCO \\
\hline Jim Petersen & Lennar Ventures \\
\hline Ben Polichnowski & Escore Program at TVA \\
\hline Christopher Schumacher & Building Science Labs \\
\hline Clarence Tolbert & NCFI Polyurethanes \\
\hline Theresa Weston & DuPont \\
\hline Shanzhong Yuan & Home Innovation Research Laboratory \\
\hline
\end{tabular}

National Lab and DOE Participants (4 DOE and 7 National Lab participants)

\begin{tabular}{|l|l|}
\hline Doug Brookman & Public Solutions \\
\hline Karen Sikes & Sentech, Inc. (note taker) \\
\hline Bahman Habibzadeh & DOE Building Technology \\
\hline Sam Rashkin & DOE Building America \\
\hline Eric Werling & DOE Building America \\
\hline Jeremy Williams & DOE \\
\hline Stacey Rothgeb & NREL \\
\hline Jon Winkler & NREL \\
\hline Andre Desjarlais & ORNL \\
\hline Roderick Jackson & ORNL \\
\hline William Miller & ORNL (note taker) \\
\hline Simon Pallin & ORNL \\
\hline Pam Cole & PNNL \\
\hline
\end{tabular}




\section{Action Items}

- Survey needed in all climate zones to better define the interior boundary conditions and to include those parameters that influence it (i.e., air exchange rate $(\mathrm{ACH})$, occupant lifestyle, roof, wall and window R-value, percentage fenestration etc.).

- Contact Google (NEST Learning Thermostat), Home Depot, Lowes, Target and other home improvement centers for potential collaboration. Source of data needed for documenting the effects of occupancy habits on interior moisture loads.

- Implement program to limit the educational gap in technology transfer to the builder. Broadcast of experience demonstrating the successful implementation in all climates. The more the support and the more knowledge provided the building community, the better the acceptance of code changes by the building community.

\section{Meeting Minutes — Morning Session (May 18, 2015)}

Sam Rashkin of the DOE started discussion with some thought provoking questions to help start dialogue among all participants "What does success look like for building energy efficiency and durability? What new technologies will evolve for moisture management solutions in buildings? How should the building industry manage the risk to building durability which is affected by code changes and craft competence?"

Joe Lstiburek of Building Science countered Rashkin's $1^{\text {st }}$ question with success being judged primarily by the demand for a product. The more the product improves building efficiency and durability the more will be its demand by building contractors. There is a need for market ready solutions that are both easily installed and cost effective. Achilles Karagiozis of Owens Corning reinforced Joe's comments of cost effectiveness but added the concept of product forgiveness for handling risk as diurnal and seasonal loads change. In other words, you can build a perfect wall, but a perfect wall is likely not cost effectiveness, so what can pass as sufficient? Who bears the risk?

Risk management and loads quickly became the focus (hot topics) of discussion. Risk was defined as the probability that a given construction would not be compromised by heat and water damage. The risk is however strongly affected by the load. Participants defined load as the interior and exterior movements of water. ASHRAE 160 "Criteria for Moisture-Control Design Analysis in Buildings" provides guidance for the large majority of homes; however, interior boundary conditions are not well understood. Lstiburek and others stated that the external temperature and hygrothermal loads are well documented by weather databases as are the ground loads but the interior loads are not well defined because of occupancy habits. Surprisingly many homeowners operate their HVAC at a set point temperature and relative humidity that is well outside the comfort zone defined by ASHRAE Standard 55-2010. People operate their HVAC at higher indoor relative humidity and are happy with 70 to $75 \% \mathrm{RH}$. Although the amount of time that people will accept the 70 to $75 \%$ RH range is unknown so it is difficult to judge the response time and subsequent effects of the internal moisture load on the structure. The house is designed for $30 \% \mathrm{RH}$ in the interior but the homeowner accepts $70 \% \mathrm{RH}$. The higher RH yields higher interior moisture movement which in turn can causes higher risks to the structural integrity of the building. Specifically, wood rot impacts the structural strength of the building components. Hence there is greater risk which industry cannot judge without more data. 
Attendee's suggested that a survey was needed to review as many homes as possible (implied thousands in all climate zones) to better define the interior boundary conditions and to include those parameters that influence it (i.e., air exchange rate $(\mathrm{ACH})$, number of occupants, building age, occupant lifestyle, building size, roof, wall and window R-value, percentage fenestration etc.). Even a preliminary generalization would provide much better data than anything currently available. Chris Schumacher stated his company conducted a survey some 15 years ago but did not have current data for buildings in Canada. Some offered that Google's initiative with the NEST Learning Thermostat may be a source of data revealing the effects of occupancy habits on interior moisture loads, perhaps a substitute for field testing. It was also suggested that Home Depot, Lowes, Target and other home improvement centers may have databases worth reviewing. The Insurance companies may also be willing to collaborate. Lstiburek also suggested Builder 20 groups as opportunity to obtain data since they span numerous geographic regions and are usually not direct competitors. In general, consensus was that organizations will be more willing to participate in the data gathering process if they knew the data would be aggregated with other inputs.

At this point, Doug Brookman shifted the topic of discussion to address five key topics Materials Properties Development, Field Testing of Assemblies, Fenestration, Codes, and Other Roadmap Issues - directly from the RFI where help was needed addressing specific comments.

1. Materials Properties Development. With regards to the need for material property data and hygrothermal modeling efforts, A. Karagiozis stated that the National Labs should not be conducting more hygrothermal material property characterizations. Industry is doing the job conducting the testing on an as-needed basis. He recommended that the National Labs serve the role of standards development for methodology, for performance of materials and for testing of assemblies. Lstiburek agreed. A need for this documentation to be easily accessible to the public was also noted, preferably through a single database so parties do not have to get in contact with individual labs.

2. Field Testing of Assemblies. We as an industry must understand what is occurring at the building level. Regarding the need for monitoring protocols to be developed and mandated (as mentioned in RFI feedback), a participant indicated the need for at least three separate protocols - energy, durability, moisture, and thermal comfort. The approach is essential as buildings become tighter. Common metrics and standardized reporting are needed to be able to quantify what the data means. Proper documentation with specific methods laid out for each step is critical to ensure that results will be "apples to apples."

Researchers and code officials are using models incorrectly to explain the physics. Their boundary conditions are not necessarily correct. Rather use the model with the field measured boundary conditions to predict the energy (heat), the moisture movements (durability) and the comfort inside the occupied space.

Regarding a timeline for "validate/demonstrate" phases, priorities must first be set to determine what is most important, and then testing protocol is needed, which must be vetted and finally agreed upon by experts. 
3. Fenestration. RFI responders noted that performance topics related to window and attachment systems that dominate much of the "real world" of builder challenges should be addressed in the roadmap, i.e. air and water leakage. Therefore, flashing is of paramount importance to handle the water and air leakage since windows is where most water and air comes in. Retrofit jobs are risky because the full window is often replaced, and the window-wall flashing construction is assumed. The overall heat transfer coefficient (U-value) and the solar heat gain coefficient (SHGC) are good measures for windows; however, as windows increase from single- to double- to triple-pane glazing the inclusion of the U-value for the frame was considered important by C. Schumacher. The framing has a more predominant effect on the U-value for a triple-pane as compared to double-pane.

Regarding limitations to achieving higher performance walls created by the status quo acceptance of windows with frame depths of 1 to $1 \frac{1 / 2}{2}$ inches (specifically mentioned in an RFI response), Lstiburek noted that the solutions already exist. Instead it is a communications and technology transfer issue; the people who need the information don't have it.

4. Codes. RFI feedback suggested a lack of guidance for hybrid insulation strategies in the code, specifically the ratio of permeable to impermeable insulation and an explanation of how it is derived. Lstiburek stated that he proposed putting in an equation in the IRC but some thought it was too complicated, and a simpler answer was needed. He suggested that a narrative be written up on where the numbers came from (combination of field testing and experience). The question remains on whether the code should be changed to include this now. Furthermore, compromises in what was included in the code resulted in several options not being allowed to be taken off the table, leading to confusion and reluctance for industry to rely on the information.

Another RFI input was that BA should work with ET and Codes and Standards to rethink performance targets for windows. Participants noted that this has already been done once with total energy ratings which combined thermal considerations and solar considerations into one. A starting point could be an energy rating to see if it makes sense and if it could be improved upon. Why go through the extra work when a considerable amount of the work has already been completed. One participant suggested that the targets must be dependent on region and building technology at a minimum.

5. Other Roadmap Issues. Brief discussion continued on the role of the National Home Builders (NHB) as compare to the BA role. Should BA take the leadership role or should BA complement NHB's work? One suggestion was to let industry determine what is cost effective and buildable, and let BA and industry move together to push technology into the marketplace. The question was not answered but it was noted that the next IECC code hearing occurs Jan 2018.

The need for research on air tightness over time was mentioned in an RFI response. Participants identified UV stability, moisture stability, and temperature stability as the three most important research topics, in that order, for buildings. 
Concerning the need for greater emphasis on foundation components, participants noted that the primary problems have been big holes that require significant repair, not cracks that need caulking.

One RFI response indicated that the roadmap should recognize the importance of climatic variability with climate-specific solutions and guidance. Participants responded by stating that the issue is the transition from above grade to below grade, and vapor diffusion and surface bridges offer room for improvement. People have traditionally accepted that basements are supposed to be damp, but more people would want basements if they felt like above grade rooms.

To close out the morning session, Doug Brookman asked what the emerging technologies are that might alter the BA roadmap, and should the roadmap consider the development and/or risk assessment of some of the more exotic technologies (e.g., phase change materials (PCMs)? Attendees concluded that it may be useful to have outputs from studies but not frame a section of a roadmap around their development until they have established a sizeable market share. Specifically, consensus was that PCMs should not be excluded as a potential technology, and vacuum panels should not be included because of durability and reliability issues. One nail in the wrong place eliminates its effectiveness. Attendees suggested that the DOE develop a listing of relevant heat transfer and moisture transfer computer tools.

\section{Meeting Minutes — Afternoon Session (May 18, 2015)}

Doug Brookman and Roderick Jackson started the afternoon session by displaying the Table 1 listing of wall systems and requested that participants judge risk in terms of implementation and technology challenge. Dialogue was diversified among participants for application of the walls in different climates, and numerous suggestions were made for potential reorganization of the table but ultimately the original structure proved to be the most appropriate.

The three wall systems in Table 1 constitute $95 \%$ of all residential wall constructions and work well in hot climates. However, study is needed for cold climate applications. Increasing the level of insulation for wall option 1 will reduce heat transfer but will cause risk of condensation in cold climates. Where should the vapor barrier be located in the wall?

With wall option 2, energy code issues were raised. Consensus of the participants believed there to be an educational gap in technology transfer to the builder. Where is the field experience demonstrating the successful implementation in all climates? Builders are aware of failures occurring as codes call for increased levels of insulation. Concern is that code increases are increasing and not alleviating building risk. The more the support and the more knowledge provided the building community, the better the acceptance of code changes by the building community.

Attendees stated that wall option 3 had no moisture problems provided the R-value was adequate. Going to heavier claddings would cause problems of finding the stud for properly fastening the cladding. A smart gun would be of great help to craftspeople to quickly locate the stud. 
A set of risk factors were formulated that included structural, drying, vapor, air and moisture metrics. Some discussion focused on the EIFS wall (i.e., exterior insulation finish system). How much insulation was needed exterior to the sheathing to protect against the potential risk of condensation on the interior side of the OSB sheathing?

Table 1: Risk Management Issues for Wall Systems.

\begin{tabular}{|c|c|c|c|c|c|c|}
\hline Option & $\begin{array}{c}\text { Wall } \\
\text { Description }\end{array}$ & $\begin{array}{l}\text { Condensation } \\
\text { Inside the } \\
\text { Wall Cavity }\end{array}$ & $\begin{array}{c}\text { Quality } \\
\text { Installation } \\
\text { of } \\
\text { Insulation }\end{array}$ & $\begin{array}{l}\text { Impact } \\
\text { Resistance }\end{array}$ & $\begin{array}{l}\text { Structural } \\
\text { Support } \\
\text { for } \\
\text { Cladding }\end{array}$ & $\begin{array}{l}\text { Quality } \\
\text { Man. } \\
\text { for } \\
\text { Multiple } \\
\text { Trades }\end{array}$ \\
\hline 1 & $\begin{array}{r}\text { Insulated } \\
\text { Framed } \\
\text { Cavity Wall } \\
\text { (Single or } \\
\text { Double) }\end{array}$ & & & & & \\
\hline 2 & $\begin{array}{r}\text { Insulated } \\
\text { Framed } \\
\text { Cavity Wall } \\
\text { with } \\
\text { Insulation } \\
\text { Sheathing }\end{array}$ & & & & & \\
\hline 3 & $\begin{array}{r}\text { Uninsulated } \\
\text { Framed } \\
\text { Cavity with } \\
\text { All } \\
\text { Insulation } \\
\text { Outboard }\end{array}$ & & & & & \\
\hline
\end{tabular}

Discussion moved to the topic of unvented attics. The building codes do not provide the full physics of moisture movement in sealed, semi-conditioned attics. Why? Because it is still poorly understood and field data is still needed to document moisture movements. Air leakage, vapor leakage and duct leakage are all confounding issues to the problem of properly sealing and controlling moisture movement. Specific to hot humid climates, increased risks were related to equipment failing quicker and vapor accumulating in the permeable insulation sheathing overnight (i.e. ping pong effect).

Foundations were also briefly discussed and participants agreed that 9 out of 10 moisture problems with foundations occur because of poor or incorrect backfill. Participants viewed foundations as an implementation issue. For hot humid climates, this was less of an issue because concrete slabs are more common than traditional foundations. 


\section{Wrap Up - Inventory of Consortiums Offering Help}

Doug Brookman finished the all-day session with request for the consortiums or working authorities that could provide continued support and guidance to the roadmap work. Participants identified several opportunities, these being:

1. EPA Indoor airPLUS Technical Guidance: Moisture Control

2. American Chemical Council

a. Work on foam sheathing, building code requirements, gap analyses

3. California Energy Commission, EPIC (Electric Program Investment Charge)

- High-R-Value Walls and Attics

4. NRCan (National Non-Destructive Testing (NDT) Certification Body)

- High performance wall study at Waterloo University

5. NRC (National Research Council Canada) Institute for Research in Construction

- Paper on Hygrothermal Analysis of Above Grade Walls (by Saber et al.)

6. ASTM (American Society of Testing and Materials)

- Series of special technical publications on thermal and hygrothermal testing of materials and building systems

7. PROSOCO

- National Corporation manufacturer of innovative products to improve the appearance and performance of the built environment

- Can test permeability of building components

8. Thermal Performance of the Exterior Envelopes of Whole Buildings XIII International Conference (2016)

9. IEA Energy Conservation in Buildings \& Community Systems: Annex 55 Reliability of Energy Efficient Building Retrofitting - Probability Assessment of Performance \& Cost (RAP-RETRO)

Brookman also asked participants what they viewed as keys to a successful implementation of the roadmap by DOE. Echoed from early sessions, most feedback was associated with making improvements to code that provide better guidance to builders, particularly related to moisture issues, were expressed. Participants also felt that the most important goal of the roadmap is the proper hand-off to the market, i.e. the final deliverable should not be a report but instead a metric that can be utilized by end users (e.g., Energy Score). Builders are nervous about upcoming changes related to air tightness and ventilation, and they want/need proper guidance and good information.

\section{Closing Remarks from Eric Werling included the following key takeaways:}

- Everyone agrees that the perceived risk is high on what we are trying to tackle in the roadmap, but overall no major structural changes are needed.

- Huge challenges remain for developing a framework for covering all R\&D priorities; this includes the need to address codes and standards reform/improvement. To cover everything we need to cover in the necessary level of detail, follow-up is going to be required, so participants will be asked for additional feedback/inputs as questions arise. 
- Next year, teams will be set up to tackle each of the major challenges identified in the roadmap. 
COMMERCIAL TRACK BREAKOUT SESSION: WINDOWS AND SHADING, MICHELLE COATES, MODERATOR

SNEH KUMAR, ALCOA/KAWNEER “DESIGN AND PRODUCTION

ENGINEERING OF HIGHLY INSULATING (R5) COMMERCIAL WINDOWS”

Mr. Kumar is the business technology leader for Alcoa's Global Building and Construction Systems (BCS) at the company's corporate R\&D Center near Pittsburgh, PA. He is responsible for the planning, development, and execution of product and process technology projects for the BCS market. He has been a member of the Board of Directors of the National Fenestration Rating Council (NFRC) since 2009 and is currently a member of the NFRC Executive Council. Mr. Kumar completed his bachelor's and master's degrees in mechanical engineering from Indian Institute of Technology, Madras, India, and University of Massachusetts, Amherst, respectively.

Mr. Kumar gave a brief overview of Alcoa's history, from its innovative manufacturing methods - which transformed aluminum from precious metal to commodity, to pioneering novel aluminum applications, to leadership in multi-material solutions. Alcoa is now a global leader in the business of architectural aluminum systems, including curtain wall, framing, windows, entrances, and sun control.

Mr. Kumar presented a graph to illustrate a striking point: the building envelope drives 57\% of the energy load. In light of this fact, fenestration clearly matters a great deal. High-performance windows can help save energy; however such technologies must be cost-effective, or they will not be widely implemented. These circumstances led Alcoa to partner with DOE to develop the highly insulating (U-factor $~ 0.22$ ) and cost-effective R5 windows. These windows deliver high thermal performance without compromising architectural strength (AW rated per the National Fenestration Rating Council), he said. Elements that enable this unique set of features include aluminum components, advanced framing systems, triple glazing, and warm-edge spacers. Their cost-effectiveness is enhanced via manufacturing capabilities and productivity improvements, including a significant degree of process automation, he said.

Mr. Kumar noted two such process improvements that stand out. First was an upgrade to the thermal-break assembly line. Combining knurling with insertion eliminated a processing step, permitting increased throughput, reduced labor input, reduced profile change over time, optimized process layout, automated profile changes, wider thermal break profiles, and generally improved quality. In conjunction with this line upgrade, implementation of an R10 glazing capability with a warm-edge spacer system increased the glass yield by $10 \%$; automated edge deletion and insulated glazing unit handling; and improved ergonomics, efficiency, and quality.

He stated that this product suite represents an industry first: R5 insulation on an aluminum window. The windows deliver $40 \%$ better thermal performance compared with other structurally strong windows while maintaining an architectural (AW) structural rating - the highest possible rating for windows, he said. A wider thermal break and triple glazing enhance condensation resistance and deliver comfort for building occupants. Aluminum construction will never rot, 
warp, or buckle because moisture or weather exposure. Further testifying to their physical strength is the successful completion of blast and hurricane impact testing. Finally, since windows must be aesthetically pleasing, the OptiQ RF window series features minimal sightlines and offers the flexibility of varied interior and exterior finishes, he said.

OptiQ thermal windows were commercialized in less than 2 years, with the fixed projecting casement configuration launching in 2012. Fixed single-hung and double-hung and single-slide and double-slide models established commercial presences in 2013 and 2014, respectively.

Barriers to wider adoption of R5 windows include the following:

- The prevalence of a code-minimum culture

- A bias in favor of proven technologies

- The general complexity of windows and their project-dependent nature

- Determining the true ROI for innovative technologies

- Economy of scale disadvantages faced by innovative technologies

- Factors other than energy (e.g., aesthetics, reliability, who pays for what)

- Awareness (e.g., that windows can be blast-resistant and offer thermal performance)

HELEN SANDERS, SAGE ELECTROCHROMICS, INC. "EC GLASS FOR NEXT GENERATION OF SUSTAINABLE BUILDINGS"

Ms. Sanders has 20 years' experience in the glass industry and more than 15 years' experience in dynamic glass technology and manufacturing. Currently, she is responsible for SAGE Electrochromics' technical business development. She generates product awareness through market education; develops strategic relationships; provides technical sales support; leads SAGE's technical development, learning, and training; and is active in codes and standards development. Since 1999, she has held a number of diverse positions, most recently leading the company's manufacturing, engineering, and solution delivery operations. Ms. Sanders has held leadership roles at SAGE in product development, manufacturing process development, and project management.

Ms. Sanders began her presentation with an overview of electrochromic glass and its ability to tint and clear on demand to reduce solar heat gain or loss without the use of blinds. In winter, this technology maximizes light admission and allows a reduction in electric light usage. Dynamic glazing with lighting controls and high U-factor fenestration IS a net-zero-energy technology, she said. Net-zero energy building performance requires the ability to block and permit solar energy as needed to optimize energy flow through the building.

Dynamic glazing collapses the solar control function into the glass itself, eliminating the need for internal and/or external management elements. Current technology requires selecting a point on the curve of visible light transmission and solar heat gain and remaining there. In this paradigm, compromises between the two are inevitable, Ms. Sanders pointed out. Double- and triple-silver 
coatings, although they may be significant upgrades, still exhibit high glare. Electrochromic glass effectively offers multiple pieces of glass, and their differing attributes, in one platform.

The combination of low U-factor fenestration, dynamic solar control, and dimmable lighting controls may amount to annual energy savings of 2.6 quad compared with the current building stock, she said. Theoretical and applied research has demonstrated that the most energy-efficient building has windows and harvests sunlight. Further, reducing energy use intensity to 20 $\mathrm{kBTU} / \mathrm{ft}^{2} \cdot$ year on the path to net-zero energy buildings will require dynamic integrated facades; such technologies are the future.

Research demonstrates that daylight and views to the outside are needed in buildings for the health of the occupants. Contrast these findings with historical building trends: cavernous, largefootprint structures dependent on inexpensive electricity and possessing relatively little natural light. The overarching challenge of the 21 st century lies in making buildings healthier for people while delivering low energy consumption, all without impacting thermal and visual comfort, said Ms. Sanders. Electrochromic glazing can deliver this convergence with the aid of complementary innovative technologies.

To deliver the energy savings that current building codes are assumed to provide, glare control is needed. But often, after periods of glare pass, manual blinds are not pulled up again; that practice increases lighting demand and energy usage.

As a result of better leveraging of solar energy — converting it from foe to friend - dynamic glazing enables HVAC technologies that otherwise would not be feasible. Dynamic glazing reduces the solar energy load on buildings and the variance in loads, permitting energy-saving HVAC technologies, Ms. Sanders said.

Beyond standard measures of performance, improvements in "human factors" are of great significance. A savings of $10 \%$ in energy usage pales against a $1 \%$ savings related to personnel—such things as improved productivity, reduced absenteeism, and retention.

Ms. Sanders then transitioned to an overview of the current market landscape. Dynamic glazing is readily available, with installations going back to 2013. Large-volume projects using architectural-size windows have been successful. Multiple suppliers exist, as do numerous proof of concept installations domestically and abroad.

Market barriers to advanced glazing (Figure 2) include retarded client buy-in due to a focus on traditional ROI measures, she said. The customers who buy such products do so not for energy savings but rather for hard-to-quantify benefits, including the dynamic design freedom afforded and human factors. These motives are neither well understood nor well communicated. There are disconnects between developer-occupied and owner-occupied buildings. Developers tend to care little about occupant comfort but concern themselves primarily with pleasing aesthetics and the ability to charge high rents as a result. Owner-occupiers more intuitively grasp the value of human factors. 


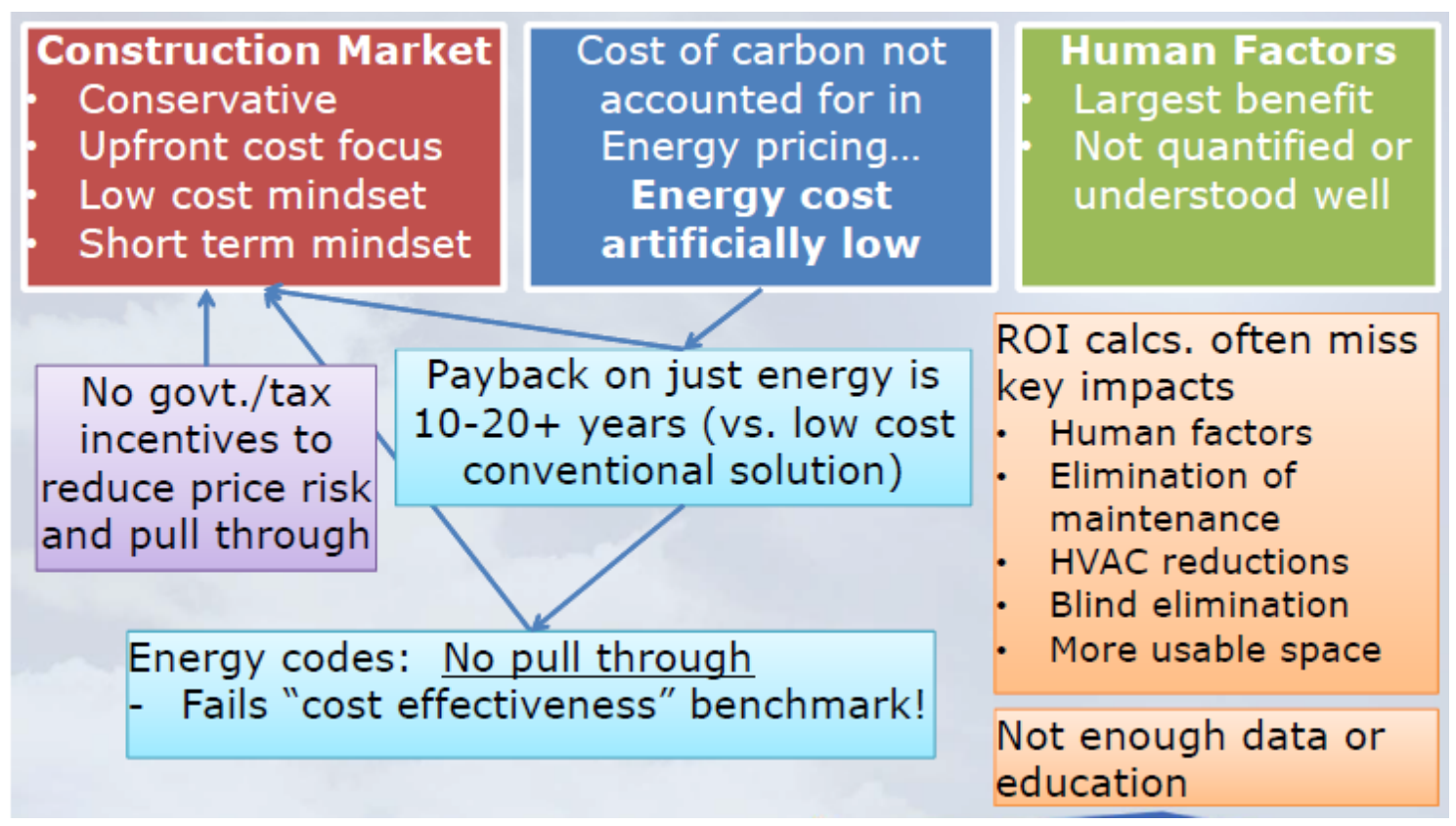

Figure 2: Market barriers to adoption.

JOHN CROWLEY, VICE PRESIDENT, ROLLEASE “ATTACHED ENERGY RATING COUNCIL PROGRAM UPDATE”

At Rollease-Acmeda, Mr. Crowley leads the development of next-generation fenestration attachment systems (e.g., window films, blinds and shades, storm windows, shutters). He also serves as vice president and technical committee chair of the Attachment Energy Rating Council (AERC). Mr. Crowley has founded a number of innovative companies in the building sector that are based on introducing disruptive technologies such as Bath Simple, a business model that has transformed bathroom renovation practices. As president of New England Classic, he developed, manufactured, and established market channels in Japan and the United States for a portfolio of interior architectural products. John served as a research faculty member at Massachusetts Institute of Technology as the director of its Innovative Construction Technology Program, a multinational, industry-supported program focused on advanced materials and systems development.

Mr. Crowley joined Rollease to work on fenestration attachments. His work led him to identify a key problem: the lack of consistent, transparent, accurate, and credible rating, labeling, and certification procedures for fenestration attachments. No organization was then responsible for collecting, analyzing, and distributing such data. Thus was born the AERC, an independent, public-interest, nonprofit organization. Its mission is threefold: to create credible rating, labeling, and certification procedures for fenestration attachments; to help architects, designers, utilities, building owners, and consumers make informed decisions; and to enable end users to assess energy costs and benefits of rated products. 
Why is this endeavor important? Despite substantial energy savings opportunities, the market often dictates that window replacements are too expensive, he said. Contrasted with

replacements, fenestration attachments are readily available, cost-effective technologies with high energy savings potential. However, major barriers exist to widespread adoption of such products. First, there exists no consistency in performance rating protocols and thus no way to identify the best products. As well, there was previously no organization responsible for creating a credible, accurate, transparent rating program for attachment.

The AERC is the result of a cooperative agreement between DOE Energy Efficiency and Renewable Energy and the Window Covering Manufacturers Association (WCMA) launched in the fourth quarter of 2014. It features an inclusive membership structure and targets financial self-sufficiency at the end of an initial 4 year funding period (total funding up to $\$ 1.6$ million). There is to be a minimum $35 \%$ industry cost-share, in addition to parallel Lawrence Berkeley National Laboratory (LBNL) investments of \$1 million annually.

AERC's main objectives are

- Develop energy performance-based rating and certification standards and procedures for fenestration attachments.

- Coordinate and interface with LBNL work on fenestration attachments.

- Oversee the implementation of AERC procedures and certification protocols.

- Develop and maintain a publicly searchable database of fenestration attachment materials and products.

- Educate and inform stakeholders.

The US fenestration attachments market is a highly developed one worth $\$ 3.5$ billion annually, Mr. Crowley noted. Estimated energy savings from wide adoption of commercial attachments are $54 \%$ over the base case.

Beyond energy savings, attachments support daylight management, which requires materials rated for design and aesthetics. Factors such as fabric openness and transmittance are critical to performance, as are consistent and reliable metrics for evaluating those factors across products and platforms.

In a similar vein, fabric solar reflectance is a key factor in the amount of HVAC energy used in a building, and automation provides a substantial reduction in lighting energy. Again, however, reliable tests and measurements are needed to foster adoption of attachment technologies.

Mr. Crowley said AERC's technical approach is threefold: prioritization of product and performance indices, characterization of key material properties, and cost-effective simulation of product performance (Figure 3). Together these efforts will result in the development of technical procedures and allow the rating of products. AERC's 2015 phase-1 focus includes cellular shades, slat shades, roller shades, and storm windows. Those are the technologies with the highest ROI currently. 


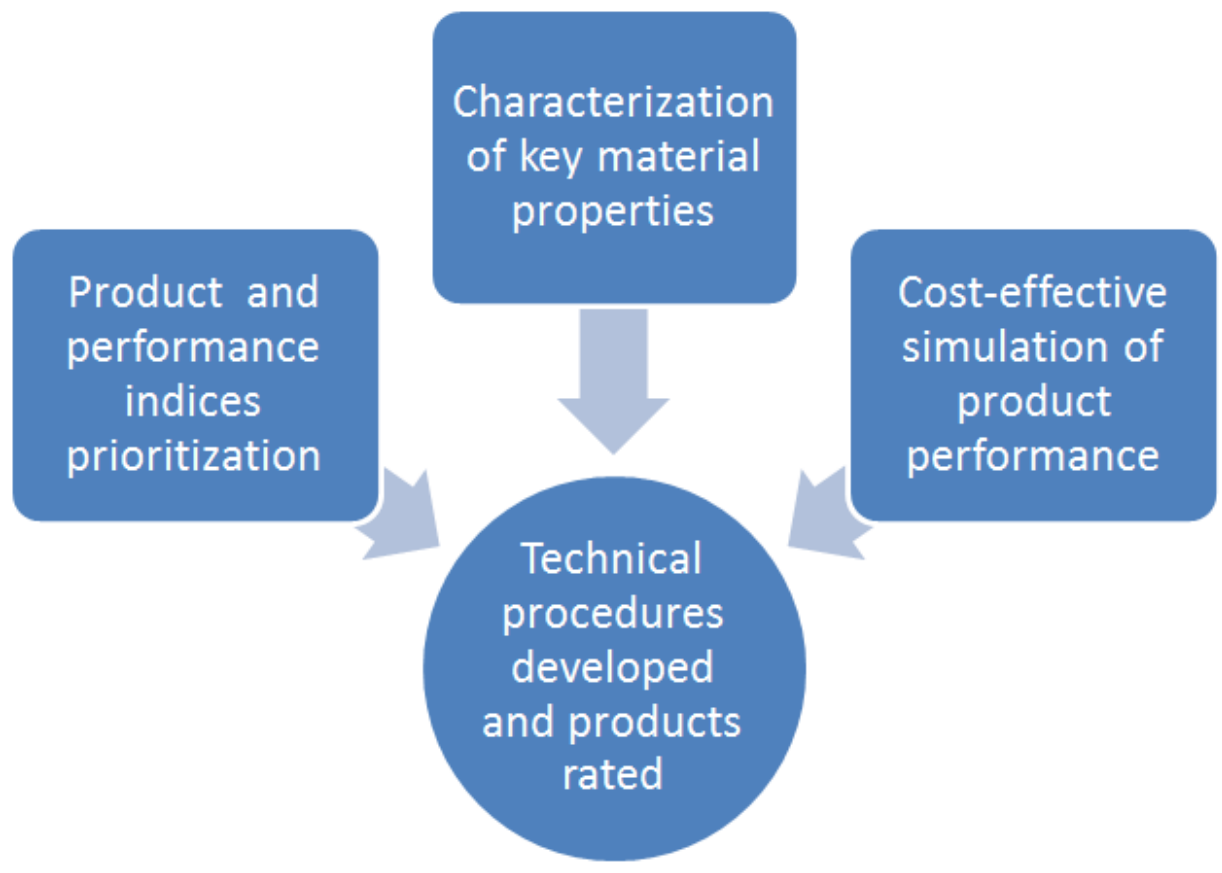

Figure 3: AERC's technical approach.

Simultaneously, LBNL aims to develop a database of validated materials that will permit early discussions with code compliance entities.

Once the relevant information is gathered and refined, it can be communicated to consumers, including architects, building owners, and end-users. These segments will need varying levels of information complexity and different transmission channels.

As an example of an existing tool that he hopes to emulate, Mr. Crowley pointed to the Lutron Performance Shading Advisor, which delivers complex data in small increments, as appropriate, to architects. They are then able to drill down into the data for their own unique purposes.

Mr. Crowley commented that the excessive focus on technical aspects in projects, rather than on delivering information via effective, tailored marketing, is an obstacle. An audience discussion ensued on this and other barriers. Participants cited barriers including building codes, including their management, inconsistencies, and reliance on metrics driven by ROI calculations that do not consider human factors.

The discussion circled back to regulatory solutions. One attendee stated that real, broad performance increases come only from government mandates applicable to all suppliers across the board. He contended that local building codes are a less effective means of coercing compliance. The lengthy code-development processes are fraught with political intrigue and competing interests; and implementation, adoption, and enforcement are subject to a myriad of jurisdictions. He reiterated his point that code changes are the most inefficient way of progressing quickly and that rule making is underused in developing new technologies. He contrasted the results of code changes with the energy-efficiency successes in appliances that have resulted from Energy Star. Such a program might solve the issue of fragmented building 
codes and improve uniform adoption. He concluded by stating that there are two methods of rapid change: mass organic consumer adoption or legislation.

Another attendee raised a point that drew not a few laughs: consumers want innovative products from multiple sources at affordable prices. Such a situation offers little incentive for innovation; a shift in mentality is necessary.

Mr. Crowley reiterated that AERC's protocols will foster innovation. There are great disparities between claimed values and experimental results for fenestration attachments. The clarity provided by established protocol, processes, and solid third-party verification of results will drive investment in publishing and validating benefits.

He concluded his presentation by suggesting that the human factors mentioned previously by Ms. Sanders are equally applicable to fenestration attachments. Positioning many envelope technologies as offering benefits not captured by traditional ROI measures may be one avenue for speeding their adoption.

COMMERCIAL TRACK BREAKOUT SESSION: NEW ENVELOPE TECHNOLOGIES

ANDRE DESJARLAIS, ORNL (ON BEHALF OF DOUG SMITH), NANOPORE "MODIFIED ATMOSPHERE INSULATION-NEXT GENERATION INSULATION MATERIAL"

Mr. Desjarlais is the program manager for the Building Envelope Research Program at ORNL. He has been involved in building envelope and materials research for more than 40 years as a consultant and at ORNL for the last 24 years. His areas of expertise include building envelope and material energy efficiency, moisture control, and durability. He has been a member of ASTM since 1987 and serves on Committees C16 on Thermal Insulation and D08 on Roofing. He has been a member of ASHRAE since 1991 and serves on technical committees TC 4.4 on Thermal Insulation and Building Systems, TC 1.8 on Mechanical Insulation Systems, and TC 1.12 on Moisture Control in Buildings. He is also a founding director of the RCI Foundation.

Mr. Desjarlais presented on behalf of Doug Smith with Nanopore. He highlighted their findings with regard to the potential energy savings opportunity that lies in modified-atmosphere insulation (MAI) technologies: using such a technology in commercial roofing and wall applications would save an estimated 2.4 quads of energy, or roughly $2.5 \%$ of all US energy consumption during 2010.

He noted that vacuum insulated panels (VIPs) with an R-value of R-36 per inch compare quite favorably to currently available insulation materials, which range from R-3 to R-6 per inch. This promising alternative has traditionally been seen as prohibitively expensive, costing $\$ 0.25 \cdot \mathrm{ft}^{2} / \mathrm{R}$ value compared with 1 in. thick foam insulation boards costing $\$ 0.06-\$ 0.10 \bullet \mathrm{ft}^{2} / \mathrm{R}$-value. Further, $25 \%$ of the cost of a VIP is attributable to material, with the remainder accounted for by 
processing and overhead. MAI offers performance comparable to that of VIP at a cost that is 40 $50 \%$ less.

Figure 4 shows how the MAI manufacturing process differs from the VIP process. Mr. Desjarlais pointed out that there are only half as many production steps in the MAI process because VIPs must be evacuated to very low pressures and sealed under a vacuum, whereas the vacuum in MAI panels results from steam condensation replacing the air.

In 2014, DOE granted funding to ORNL to conduct a scoping study for evaluation of MAI. The study entailed pilot-scale production, with the plant producing $300 \mathrm{ft}^{2}$ of MAI panels per hour in sizes from 1-1.5 by 1-2 ft. A thermal performance evaluation was conducted measuring R-value according to ASTM C518.This assessment indicated that even with a total vacuum loss, the MAI panel can be expected to exhibit higher R/in. ratings than conventional insulation materials. This ongoing study aims to substantially reduce the cost of MAI technology.
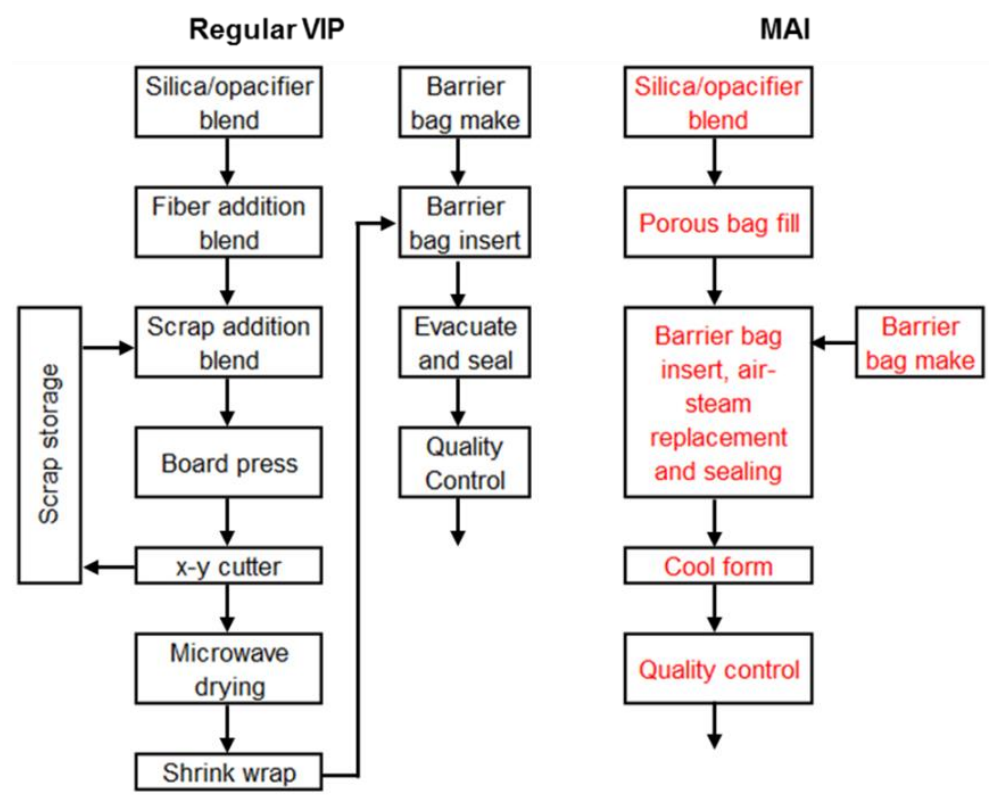

Figure 4: Distinctive production processes for VIP and MAI.

With building envelope lifetimes stretching toward 50 years, MAI panels must retain their high R-value for the duration of their use, i.e. the barrier films must reliably prevent vacuum loss. Panels must also resist damage during and following installation. Panel size must be optimized to minimize the impact of damaged panel(s) on the overall R-value of the envelope component. One potential solution lies in prefabricating components that demand minimal sizing and/or alteration on site.

The difficulty of achieving mass deployment of this technology without efficiency compromises stands as another obstacle to widespread adoption. The ideal and goal is volume production of insulation materials with MAI without any commensurate loss in production efficiency.

MAI is a lower-cost alternative to VIPs and a good candidate for next-generation insulation materials, Mr. Desjarlais concluded. ORNL and its industry partners are working on a DOE- 
funded project to develop an R-12/in. composite insulation material. Persistent technical and market barriers will be evaluated and mitigated to the extent possible. Other ongoing and proposed activities include developing an MAI siding composite and integrating MAI with additive manufacturing.

JOHN LETTS, FIRESTONE "POLYISO-ENCAPSULATED MAI (MODIFIED ATMOSPHERIC INSULATION) PANELS"

Mr. Letts is the technical director for insulation technologies in the Technology Department at Firestone Building Products Company. Before joining Firestone, he was employed at Union Carbide, primarily in urethane technology. He received his doctorate in chemistry from Ohio State University in 1982. He has 30 years of experience in urethane technology, from research and development to technical service to plant support.

Mr. Letts detailed the general concept behind polyisocyanurate (polyiso) -encapsulated MAI panels: surrounding the more fragile but high-performing MAI with the robust but lowerperforming polyiso, produced commercially in a continuous process. The target for the composite is a 2 in. thick board $(4 \times 8 \mathrm{ft}$.) with an R-value of 25 .

The advantages of this technology include a high R-value between 40 and 60, relatively simple components, and a thin profile. Disadvantages include fragility, catastrophic loss of performance in the event of puncture, edge effects, and high costs.

Polyisocyanurate offers among the highest of R-values among all commercial foam insulations, in addition to durability and a status as a proven, established technology. However, its inherently thicker profile and R-value of 5.7-5.9 are less attractive, Mr. Letts said.

The respective characteristics of each material are highly complementary, he stated. Encapsulating the MAI inside polyiso makes the composite more durable in a construction environment and minimizes edge effects. MAI reduces the materials cost and makes the overall composite more cost-competitive. Figure 5 illustrates how a polyiso-encapsulated MAI panel is structured. Note that the research team is still testing multiple designs to optimize the encapsulation. 


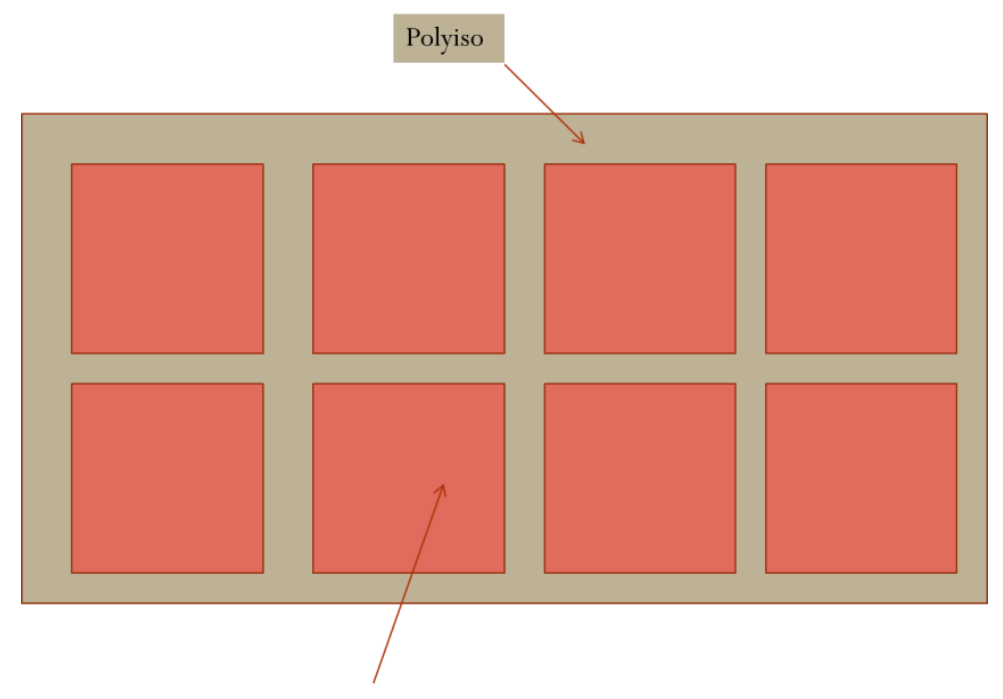

MAI

Figure 5: Example of polyiso encapsulated MAI.

As of this workshop, lab prototypes of the panels have been produced. Dimensional, pressure and temperature tolerances have been evaluated and no problems were identified, Mr. Letts said. Polyiso foam temperatures can maintain their integrity and performance at temperatures as high as $300^{\circ} \mathrm{F}$. Modeling of various MAI panels in the form of $4 \times 8 \mathrm{ft}$ boards has been concluded at ORNL.

In the near future, the research team will begin conducting a market evaluation and demonstrate commercial production manufacturing of an industrial-size composite board for large-scale evaluation at ORNL in 2015.

Mr. Letts wrapped up the discussion with a highlight of some broader challenges to adoption, including the general resistance to new products of a conservative construction market and the particulars of optimizing an encapsulation design so as to

- maximize the percentage of MAI in a typical board

- produce these composite boards economically in a commercial environment

- avoid destroying the MAI panels while cutting the composite boards

- position the MAI before introducing the polyiso

- determine how to use fasteners in the composite board and optimize their location

- enable a contractor or building owner to recognize that an MAI panel in the composite board has been punctured 
JOHN BRESHEARS, ARCHITECTURAL APPLICATIONS “AIRFLOW PANELS”

Mr. Breshears is a licensed architect and mechanical engineer with 25 years of experience in designing high-performance green buildings. He developed the concept for the product presented at the workshop with the support of the Peter Rice Memorial Prize given by Arup Engineers. With additional support from ARPA-E and DOE, the AirFlow Panel ${ }^{\mathrm{TM}}$ has been brought to market. Mr. Breshears also consulted with Amory Lovins on the design of the new headquarters for the Rocky Mountain Institute and teaches green building systems engineering at Stanford University.

Mr. Breshears said AirFlow panels cool a room with 25-50\% less energy using a space-saving technology integrated into the building enclosure. They remove heat and humidity within the envelope before these can reach the air-conditioning unit. The component achieves superior performance by taking advantage of the large space available within a conventional rainscreen or curtain wall system, he said. Figure 6 illustrates how AirFlow panels work. He listed the following features.

- Reduce air conditioning capital expenditures and operating expenditures: The panels are $89 \%$ efficient relative to conventional air conditioning (which is typically $64 \%$ efficient).

- Improve the prevention of indoor airborne mold formation: The panels remove humidity without condensing it into a liquid form, dramatically improving the indoor air quality and reducing the probability of mold growth.

- Reclaim leasable space taken up by ventilation air pathways: The panels transfer the supply and exhaust of ventilation air from the central core to voids within the envelope system, increasing the net leasable floor area.

- Are easy to install in both new construction and retrofit projects.

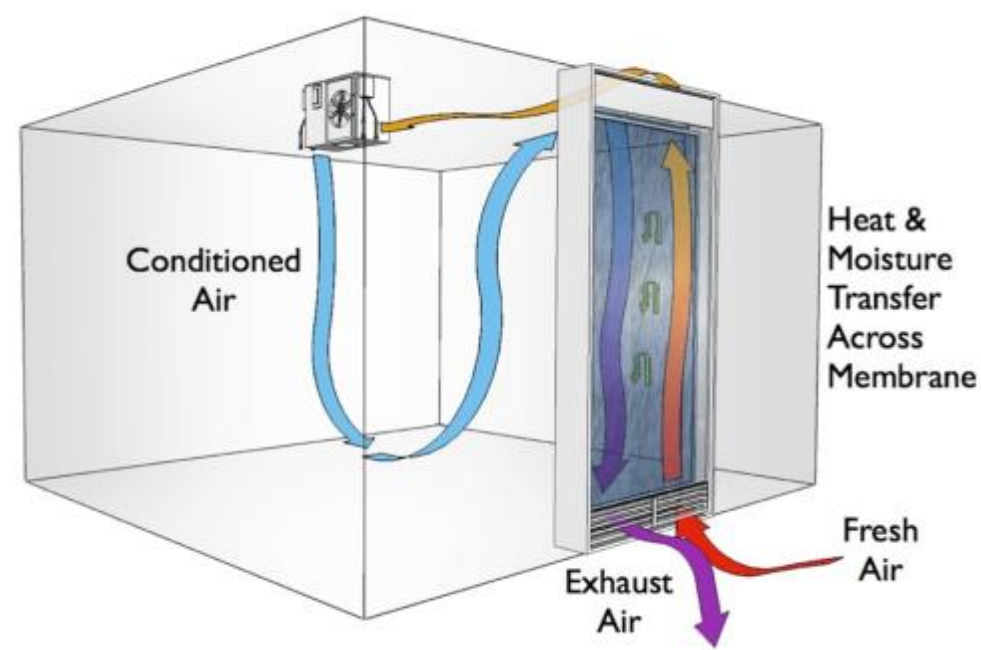

Figure 6: A simplified graphic showing how AirFlow panels work. 
According to results determined by Lawrence Berkeley National Laboratory using EnergyPlus simulations (based on a DOE-standard mid-size office building) with AirFlow panel measured and validated performance data, the panels can reduce the energy used for air conditioning by $25-50 \%$.

The panels are now commercially available in two designs. The " $\mathrm{CW}$-series" is compatible with conventional metal-framed wall systems and offered in custom panel sizes. The "RS-series" is compatible with exterior panel (or rainscreen) systems. Both designs feature custom panel sizes and finishes to match the wall system.

Barriers to adoption of the panel include the following:

- Decentralization: Use of AirFlow panels shifts air ventilation from a centralized to a decentralized approach. The shift raises concerns regarding increased maintenance and complex controls.

- Hybrid nature: Because the panels are a hybrid HVAC-insulation system, they fall between the two types of contractors. The workforce is concerned about liability, installation, and warranty issues. In general, contractors are unsure how to handle such a technology.

- Risk aversion: The construction industry is conservative, and it takes a long time to adopt new technologies widely.

SHAWN PRESTEGAARD, 3M "AIR BARRIER TECHNOLOGIES THAT CHALLENGE THE STATUS QUO”

Mr. Prestegaard is a business development manager with 3M's Industrial Adhesives and Tapes Division. He has worked in a variety of business roles within this division for the past 15 years. For the last 3 years, he has led a business team in the development and commercialization of a variety of tapes, adhesives, and coatings for air and moisture management within the building envelope.

Mr. Prestegaard discussed Air and Vapor Barrier 3015 $5^{\mathrm{TM}}$, recently developed (by 3M), and listed the following features:

- High-temperature application: The barrier membrane is a robust acrylic that can be installed at temperatures of up to $120^{\circ} \mathrm{F}$. In polyethylene barriers containing asphalt or bitumen, the adhesive can slide and peel away at high temperatures.

- Low-temperature application: The barrier can be installed at $0^{\circ} \mathrm{F}$ and remain tacky and conformable. Traditional polyethylene with asphalt/bitumen becomes stiff and loses its adhesion capability.

- Light weight and ease of handling: The barrier is about only a third the weight of polyethylene with asphalt/bitumen.

- There are no known compatibility issues for use with other materials. 
- The barrier is a translucent film.

- It is fire code compliant (National Fire Protection Association 285).

Prestegaard said 3M intends to move away from water-based latex and into silyl-terminated polyether (STPE) technology. Moisture-cured STPE is a chemically cross-linked system introduced to the construction industry more than 30 years ago and by $3 \mathrm{M}$ in 1995 . He said the polymer offers a number of advantages such as : durability, water vapor permeability, elastic recovery, ultraviolet stability, weather robustness (low temperatures, damp surfaces), and ease of application (one coat, fast cure).

He characterized STPE technology as addressing several challenges typical in water-based latex applications:

- Installation problems such as lack of adhesion on damp surfaces, slow drying in humid weather, washdown during rain, rundown, and slow curing due to thickness

- Failure in wall cavities due to moisture collecting on the horizontal surface and contributing to the failure of fluid-applied water-resistive barrier/air-vapor barriers.

- Durability: Prolonged water exposure leads to water absorption and therefore loss of recovery, loss of adhesion, swelling and bubbling. 
LUNCH SPEAKER: NICHOLAS HOLT, SKIDMORE, OWINGS, AND MERRILL (SOM) "A RETURN TO PERFORMANCE"

Mr. Holt noted that cities across the world are experiencing pressure to improve the sustainability and longevity of their building stock. New York is a great example-it is setting aggressive plans to reduce greenhouse gas (GHG) emissions. The target for the building sector is a $30 \%$ GHG reduction by 2025 relative to a 2005 baseline. Realizing such an aggressive plan requires a well-balanced approach of mandates, incentives, and market transformation activities by an engaged set of stakeholders.

An obstacle to motivating the building industry to use more sustainable techniques is the existing mindset of key stakeholders, such as real estate brokers, Mr. Holt said. Brokers demand that a building have a certain percentage of window space, feeling that window space is necessary to attract tenants. Brokers also demand over $40 \%$ glazing of building facades. The results of surveys undertaken to determine how often blinds are left open indicate that occupants do not use buildings as brokers assume they do. Tenants do not use windows for illumination, and the glass results in glare and privacy issues. Despite these issues, brokers remain convinced that glass is popular. Such misconceptions have negative energy implications for building design.

Mr. Holt referred to a project at the US Air Force Academy in Colorado Spring, Colorado, as a case study in obstacles to the adoption of energy efficiency features. A building was designed to be a signature addition to the campus, and the vision was to bring it as close to being a net-zero structure as was economically feasible. The design included photovoltaics for shading and energy generation; it demonstrated superior energy performance and could achieve LEED platinum certification. Then in the middle of the project, a bill was passed dictating that no Department of Defense building pursue certification beyond the LEED silver level. This mandate necessitated modifications to the building design. It is now completed and pending LEED silver certification. The annual energy cost is estimated at 20\% below the ASHRAE 90.1-2004 level. This example shows how changes in the political environment can impose barriers to aggressive energy efficiency and renewable energy designs.

The advancement of green designs demands innovation. On a project to design net-zero energy public schools in New York City, the SOM team was required to meet net-zero-energy standards in 3 years. One of the unique problems faced in this project was high classroom plug loads. Upon investigating the issue, the team discovered that previous policies attempted to maximize teacher time with students by providing only cramped, sparsely furnished faculty lounges. The result was increased classroom energy consumption because teachers attempted to make their classrooms more comfortable by bringing in microwaves, mini-refrigerators, and other such amenities. The new designs featured better-appointed lounges. The surplus plug load was removed from the classrooms, appreciably reducing energy consumption.

Innovation may often seem a poor investment by traditional measures, Mr. Holt noted, but it is only with bold new ideas that we truly advance. 


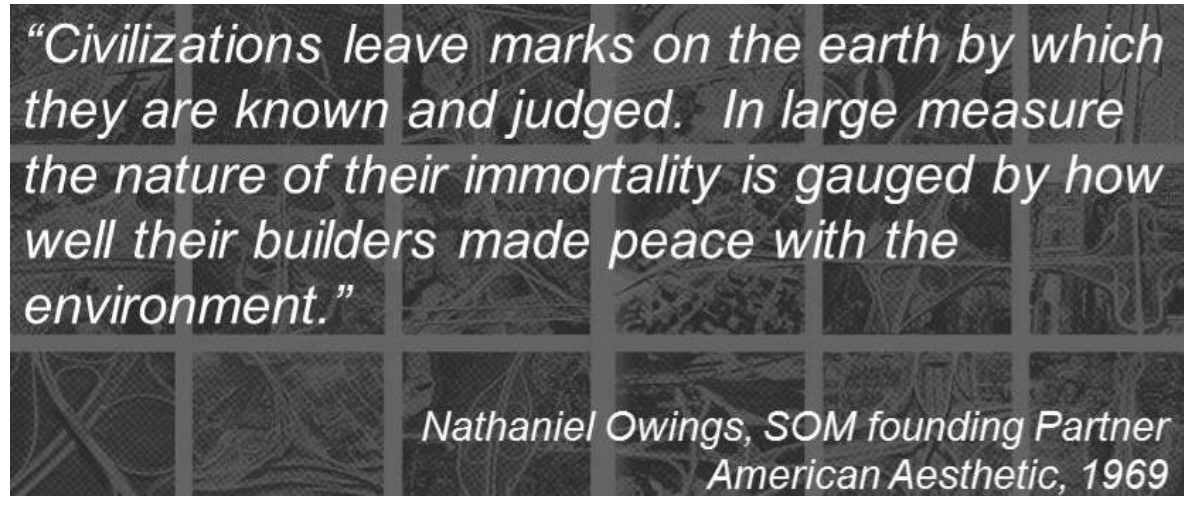

Figure 7: A closing quotation from the lunch presentation. 
COMMERCIAL TRACK BREAKOUT SESSION: ENVELOPE RETROFIT APPLICATIONS, DIANA HUN, MODERATOR

STEVE DEBUSK, EASTMAN CHEMICAL "RETROFIT ENERLOGIC LOW-E WINDOW FILMS"

Mr. DeBusk is a Certified Energy Manager, a Certified Measurement and Verification Professional, and a Certified Sustainable Development Professional through the Association of Energy Engineers. He has BS and MS degrees in mechanical engineering from Virginia Tech. He is currently the manager of Global Architectural Technical Services at Eastman's Performance Films Division. Eastman's longstanding commitment to energy efficiency includes being named an Energy Star Partner of the Year from 2012-2014 and winning the American Chemistry Council's Energy-Efficiency Award 20 consecutive times. The company's Performance Films division has manufactured window films since the early 1960s.

Mr. DeBusk said that EnerLogic is the first true low-emissivity (low-e) window film, with performance comparable to that of low-e windows (emissivity=0.07). Although other films provide summer cooling savings, Mr. DeBusk said, EnerLogic offers year-round benefits, including additional savings in summer and winter due to its improving the window U-value.

EnerLogic window film is a thin, transparent polyester film applied to the interior side of the window. It contains precious metal coatings that reflect solar heat in the summer, reducing cooling expense. These metallic coatings, in conjunction with other technologies in the film, create a low-e surface facing the building interior. This coating significantly improves the window's insulating performance, Mr. DeBusk said. Thus single-pane filmed windows become as effective as conventional dual-pane, and dual-pane as effective as triple-pane windows. These benefits come at a fraction of the cost of window replacements, he said.

He said a recent installation of $23,000 \mathrm{ft}^{2}$ of the product at the Hyatt Regency Houston yielded significant improvements measured by third-party Green Generation Solutions: $23 \%$ cooling savings, $25 \%$ heating savings, and 3.6 year payback period after rebate. It benefits extend beyond efficiency and include improved occupant comfort, reduced glare, improved natural daylighting from reduced use of shades, and reduced running time for HVAC equipment. Mr. DeBusk noted that customers do not usually purchase EnerLogic film for energy-efficiency but rather for these other factors; later, they are pleasantly surprised at the performance improvements. A common customer concern is that installation of film will block too much sunlight. However, Mr. DeBusk said, uncoated windows are more subject to glare and thus the sunlight may be wasted. Adding film, he said, permits a more appropriate amount of light. 


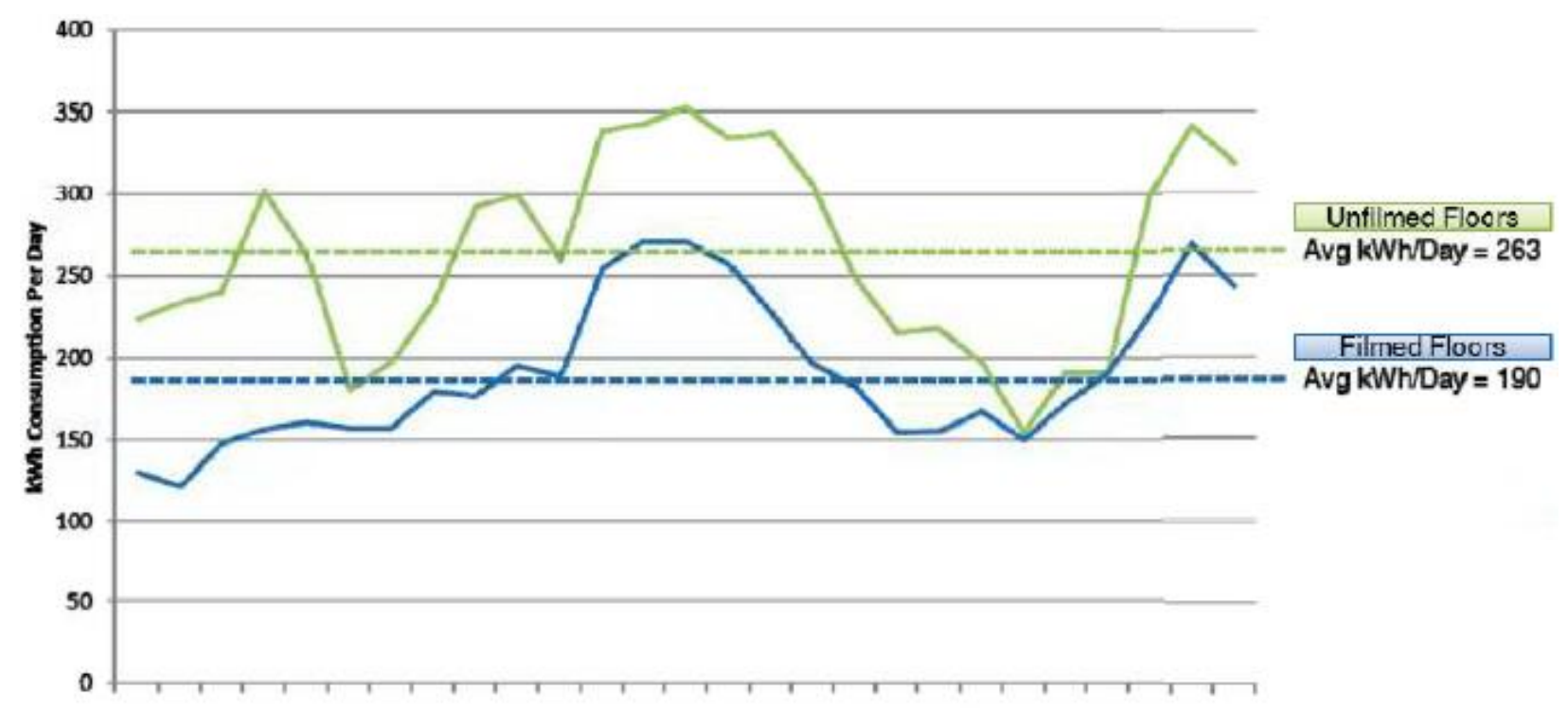

Figure 8: Comparison of winter energy consumption (in kilowatt-hour) at the Hyatt Regency Houston.

In the transitioning provider market, Mr. DeBusk said, traditional contractors have been augmented with HVAC providers, as there is a trend toward a more holistic view of the energy improvement market. He said low-e window film is a relatively easy sell given its ease of application, noninvasive nature, and favorable cost/benefit profile.

With regard to barriers to customer adoption, Mr. DeBusk mentioned that customers often do not believe the model-driven projected savings he shows them. There remains a need for real-world evaluations, such as that conducted by Eastman at the Houston Hyatt. Additional case studies are planned for Dallas and for Ogden, Utah, he said, but customers will always demand more studies relevant to their exact circumstances.

CRAIG TYLER, CARLISLE CONSTRUCTION MATERIALS "ROOF TIE-INS: NEW ROOFS WITH EXISTING AIR AND VAPOR BARRIERS”

Mr. Tyler is a licensed architect and a specification writer for Carlisle Construction Materials. He holds both masters and bachelor's degrees in architecture from Savannah College of Art and Design and has practiced architecture throughout the Midwest and Southeast on various projects with both private and public owners. As a member of the design services team for Carlisle, he is involved with code development with ASHRAE and the International Code Council and remains current with green construction programs including LEED, Green Globes, and Living Building Challenge.

Carlisle is a major producer of dark and white roofing membranes, in addition to complete building envelope products, and is the largest producer of expanded polystyrene (EPS) insulation producer in North America and of polyiso in the United States. Carlisle is established in 80 
countries with 26 manufacturing facilities in the United States and Europe and has 50 years' experience in low-slope commercial roofing.

Mr. Tyler noted that a building envelope is the physical separator between the inside conditioned space and the outside unconditioned space. Three basic elements are found in any envelope: an air barrier, a moisture barrier (liquid and vapor), and a thermal barrier. He noted that the air barrier controls air leakage into and out of the envelope, and the vapor barrier is any material that eliminates or retards the diffusion of vapor into and out of the building envelope. Some manufacturers offer products that serve both purposes simultaneously. All three elements must complement one another to provide a comfortable and efficient building.

The commercial real-estate industry spends approximately $\$ 24$ billion annually on energy, which represents the single largest controllable operating expense for office buildings, he said. As well, buildings accounted for $46.9 \%$ of US CO2 emissions in 2009. Proper building envelopes are a paramount requirement for an energy-efficient building.

The complementarity of different envelope layers is highly important in delivering maximum energy-efficiency performance. Barrier discontinuities compromise performance; transitions between envelope materials must provide a continuous seal.

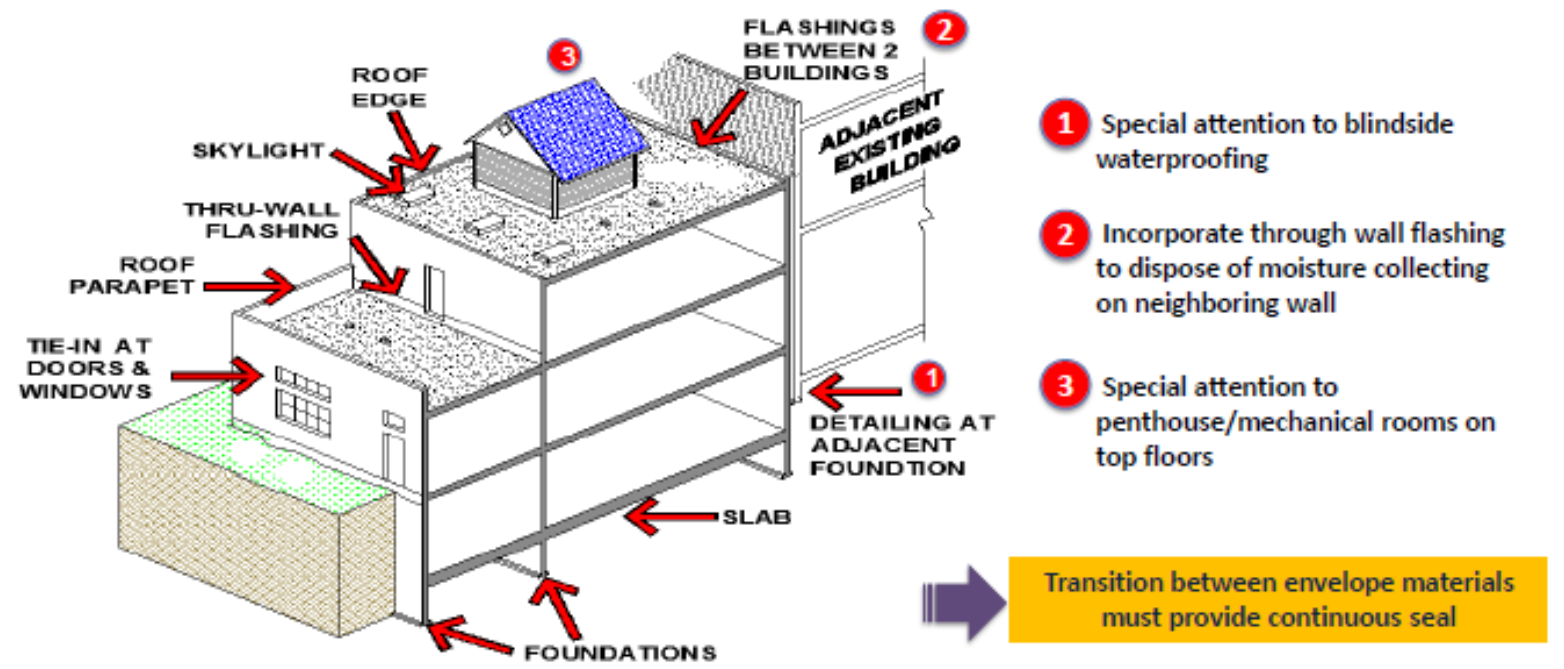

Figure 9: Critical building envelope areas.

Three systems compose the building envelope: below-grade components, walls, and roof. Belowgrade components include filter fabric, drainage board, insulation, and a waterproofing membrane. Wall assembly components include an air and vapor barrier and continuous insulation. Air/vapor barriers can be in the form of self-adhering sheets or applied by spray or roller. Placement of the air/vapor barrier is crucial, and incorrect usage of vapor barriers is leading to an increase in moisture-related problems. Vapor barriers are intended to prevent assemblies from getting wet; however, they often also prevent them from drying. Vapor barrier placement is strongly dependent on climate.

Roof assembly components include the air/vapor barrier, insulation, adhesive, and a single-ply membrane that doubles as an air/vapor barrier. The air/vapor barrier is not as critical in roofing 
systems, but the roof should be airtight to prevent leaks. Air/vapor barriers are needed on buildings that must strictly control internal moisture. The air/vapor barrier can act as a temporary roof. Single-ply roofing is one solution to moisture intrusion. It comes in three membrane options - EPDM, TPO, PVC — and many widths, lengths and membrane thicknesses.

Mr. Tyler concluded by noting that building codes are influencing demand. He expects new building codes to require roof tie-ins and is selling customers on combining air barriers with roofing.

AMY WYLIE, BAYER MATERIAL SCIENCE, "PACKAGED MASONRY WALL RETROFIT SOLUTIONS FOR SMALL AND MEDIUM-SIZE COMMERCIAL BUILDINGS"

Ms. Wylie is the buildings and transportation platform leader for Bayer Material Science in the Public Sector and Business Growth Services Division. She leads the efforts for government contracts, market intelligence, and market development support for the buildings and transportation areas of the public sector. Ms. Wylie also serves as principal investigator dedicated to the DOE-funded Consortium for Building Energy Innovation (CBEI). Her primary responsibilities include integration of roof and envelope systems into whole building integrated retrofit designs. Ms. Wylie has a BS in life science from Pennsylvania State University in 1998 and a BS in chemistry from the University of Pittsburgh. She joined Bayer Material Science in 1997.

The objective of the CBEI is to develop an integrated, energy-efficient, cost-effective wall retrofit solution for insulating the interiors of existing masonry walls of commercial buildings. The identified retrofit solution will be demonstrated on the Flexible Research Platform (FRP) at ORNL to collect field data. Project partners include Bayer, ORNL, CBEI, Carlisle, and the Air Barrier Association of America (ABAA). The project was launched in June 2013 with an anticipated end date of April 2016.

Ms. Wylie said the identified best practice recommendations were evaluated on the criteria of (1) exceeding ASHRAE 90.12010 performance and (2) offering a payback period of 10-15 years. Project deliverables include a detailed case study highlighting the performance of the demonstrated technology on the FRP wall construction (including field data, hygrothermal evaluation results, and laboratory tests), an extensive evaluation matrix comparing the performance of a number of retrofit scenarios against six critical evaluation parameters, and guidelines for best practices recommendations.

The project addresses a major market need: most old masonry buildings are uninsulated and require interior retrofits. Challenges include interstitial condensation and freeze/thaw damage.

Benefits of the project will include increased energy efficiency through improved envelope performance and reduced air leakage, improved thermal performance, and improved moisture performance/durability_all via an integrated package solution. 
Two market barriers were highlighted. First, building envelope retrofits are rarely undertaken because of their high upfront costs and lengthy payback period. Second, the constructability and practicality of construction is an important factor for retrofitting the interior sides of existing exterior walls.

An industry expert review in August 2014 assisted in designing the schema and criteria for effective testing. To this end, they developed a balanced scorecard with which to evaluate proposed solutions. Critical evaluation parameters included cost-effectiveness (35\% weight), thermal performance (18\%), air leakage (12\%), moisture management/durability (20\%), disruptiveness/constructability (9\%), and indoor air quality $(6 \%)$.

During the laboratory testing stage, Ms. Wylie said, mock-up walls were constructed and tests were run for the scenarios that passed the initial evaluation. These tests determined the most cost-effective solution to be retaining the existing wall and installing 2 in. polyisocyanurate rigid board with taped seams. This is a good solution, she said, but may not be applicable in all situations, depending on the condition of the existing wall. The most energy-efficient solution was determined to be installing 3.5 in. closed-cell spray polyurethane foam. These two scenarios will next be demonstrated on ORNL's FPR. The data will be collected and evaluated against initial evaluation data and lab test results. A detailed case study will be generated that highlights the performance of the identified best practice recommendations, and best practice guidelines will be disseminated to the market. Finally, the two selected scenarios will evaluated and their constructability compared before the commercialization plan is executed.

A commercialization and dissemination plan will use regional and annual conferences sponsored by industry associations (e.g., Roofing Consultants Institute, American Institute of Architects, Construction Specifications Institute) to disseminate the findings of the study to the construction industry. Deployment channels (e.g., marketing and technical bulletins or regional and national training) available through market partners Carlisle Construction Materials and Air Barrier Association of America will be used. Project findings will be published in journal articles. Education webinars will be organized through industry association programs to disseminate project results.

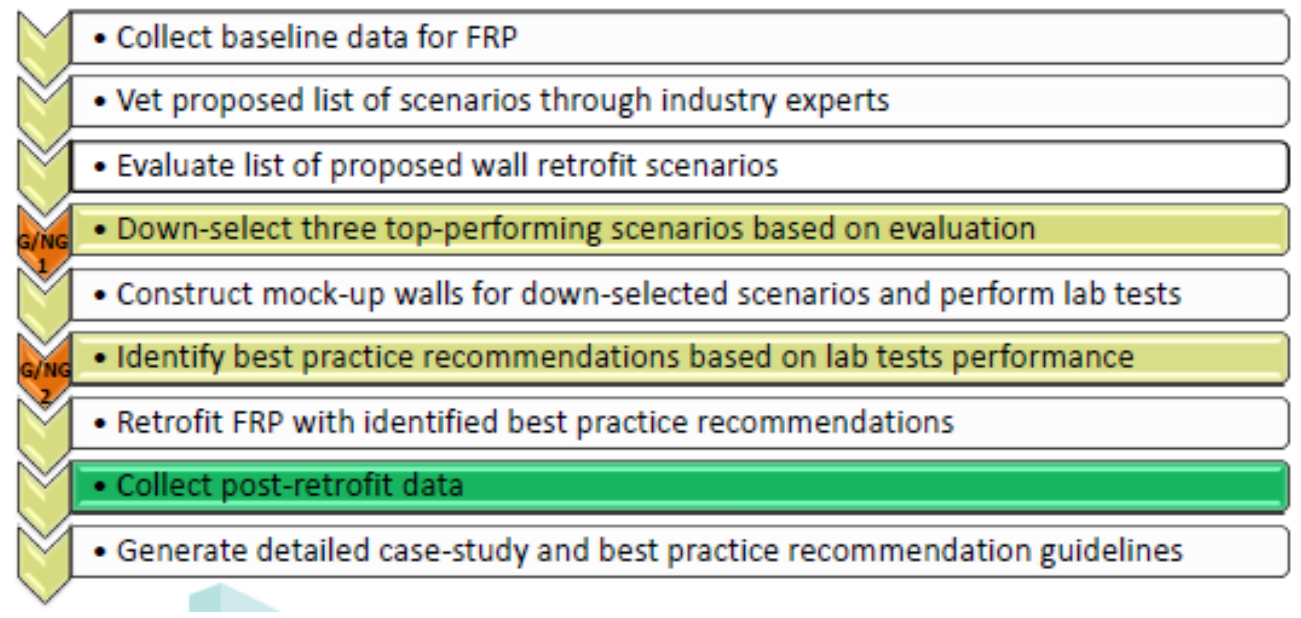

Figure 10: Overview of the solution identification process. 
With regard to adoption barriers, Ms. Wylie said there is a need to educate owners of small and mid-size buildings on the value and scope of potential retrofit solutions. This may include the development of applications that better communicate critical elements as part of a broad, wellcrafted dissemination campaign.

COMMERCIAL TRACK BREAKOUT SESSION: AIR BARRIERS

KATHERINE FABER, THE DOW CHEMICAL COMPANY “ONE-STEP SPRAYABLE LIQUID FLASHING TECHNOLOGY TO INCREASE ENERGY SAVINGS AND DECREASE INSTALLATION TIME"

Ms. Faber is a research and development chemist at The Dow Chemical Company focusing on development of new coating products for the commercial and residential building envelope applications. Her primary responsibilities include coating formulation, applications testing, thirdparty testing, and conducting field trials. Ms. Faber received a BS in chemistry from Pennsylvania State University in 2007. She joined Dow Chemical in 2008.

Ms. Faber provided an overview of Dow's LIQUIDARMOR ${ }^{\mathrm{TM}}$ coating, a durable, sprayable flashing and sealing solution for protecting the building envelope. According to her, the coating has the following characteristics:

- Easy to use with minimal training

- Conforms easily to any shape or texture

- Adheres to common building materials

- Passes ASTM air and water infiltration wall assembly tests

- Meets building and energy codes (ASHRAE 90.1, IECC, and IBC)

- Save installation labor costs

- Targets board joints and gaps around penetrations

- Is a one-step sprayable flashing:

o no backer needed for areas of $<1 / 4$ in.

O spans gaps up to $1 / 4 \mathrm{in}$. without accessories

- Can be brush applied

- Applied at $50 \pm 5$ wet mils

- Requires no measuring or cutting of flashing

- Installs 3-4 times faster than flashing tape (as measured for board joint sections in actual projects)

- Low toxicity

o similar to latex paint ( $<50 \mathrm{~g} / \mathrm{L}$ volatile organic compounds)

$\circ$ only gloves and safety glasses required as personal protective equipment

- Minimal overspray and water cleanup 
Ms. Faber described the coating's ability to control moisture and accordingly improve durability. With regard to the latter, she said, it passes AMAA 714 accelerated aging, freeze/thaw, and heat age testing and can endure real-time outdoor exposures exceeding 5 years. She stated that its ease of application and inspection, exceptional adhesion, elongation, and nail sealability combine for a highly innovative product.

\section{The elastomeric spray forms a tight, durable, seamless barrier \\ along the board joints and rough openings of windows and doors}
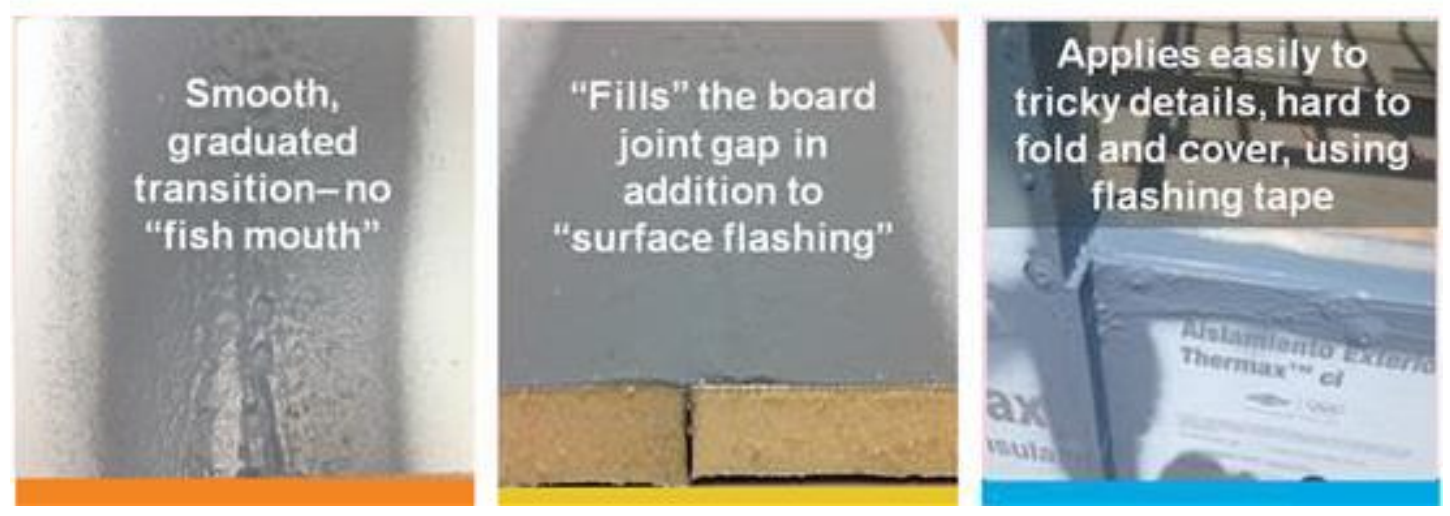

Figure 11: LIQUIDARMOR benefits.

Ms. Faber noted that like other fluid-applied products, LIQUIDARMOR faces barriers in the need to buy sprayers, overspraying, jobsite ventilation requirements and volatile organic compounds (VOCs), complex system components, field installation quality, and transition details. Even though a wide array of sprayer options are available, contractors often consider the investment to buy a sprayer a barrier. There are concerns about overspraying and about ensuring that spray is not wasted by contractors with insufficient knowledge of the degree of spraying needed. She said there have been no significant overspray complaints in advance job site planning and sequencing in commercial new construction. The coating is nonhazardous and poses no VOC danger during application, she said, and there are no special respirator or ventilation requirements. Liquid-applied products are used with rigid foam exterior insulation for broad wall coverage, and they need no special accessories in a targeted, fluid-sealed area for air, water, and thermal barrier continuity. Field installation quality issues can be remedied with proper training and brush touchup, she said.. Concerns associated with transition details are aggravated by the fact that every job has different details; the installed effectiveness of air barriers/weather-resistant barriers typically depends upon transition details being correctly predetermined and installed.

Because of the coating's ease of use and minimal required workmanship, it will be featured at the China Clean Energy Research Center Building Energy Efficiency consortium (CERC-BEE), Ms. Faber said. The goal of CERC-BEE is to develop a novel liquid flashing sealant with outstanding performance that is beneficial to both the United States and China. 
MARYSUSAN COUTURIER, WR GRACE “ENERGY SAVINGS WITH FULLYADHERED WEATHER BARRIER"

Ms. Couturier is a principal scientist with W.R. Grace. She has over 25 years' experience in research and development with polymers and holds five patents.

Ms. Couturier discussed the relative merits of fully adhered weather barriers compared with traditional mechanically attached barriers. Fully adhered barriers seal to the substrate so that they remain adhered during construction. This sealing provides resistance to blow-offs and tears in windy conditions, creates a continuous and aggressive bond, and prevents lateral water migration, she said. The fully adhered weather barrier also seals to itself, so that laps are fully adhered and aggressively bonded. Special treatment at the joints is not necessary. A fully adhered weather barrier seals around fasteners so that all exterior finishes are mechanically attached; and the adhesive forms a watertight seal around the fastener, as each penetration is a potential entry point for water. Figure 12 illustrates the significant difference in air leakage rates for mechanically attached vs. fully adhered weather barriers.

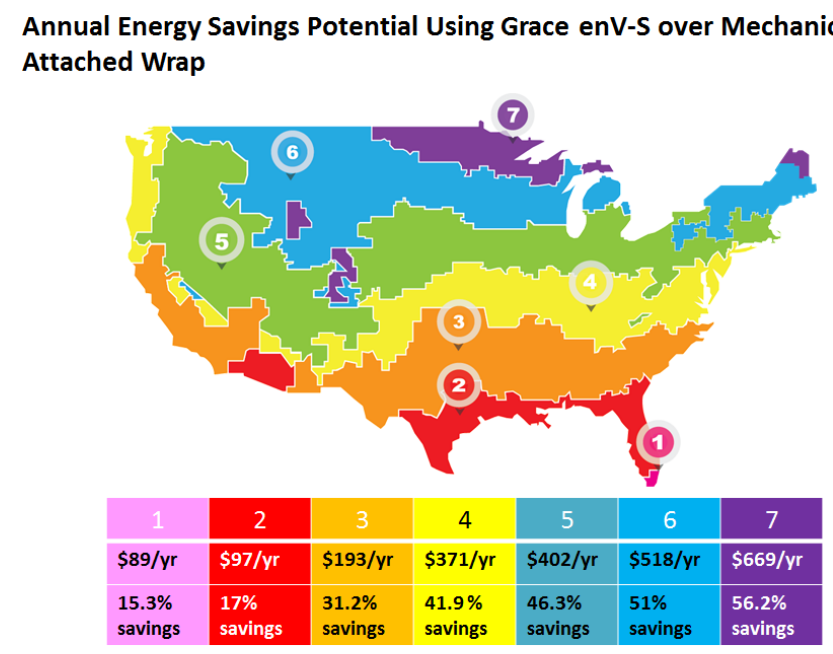

Average $37 \%$ less energy costs using fully adhered over mechanically attached WRB

Figure 12: Air leakage study results.

Computer simulations using Energy Plus to correlate air leakage and energy savings estimate average energy savings of $37 \%$ from using a fully adhered weather barrier over a mechanically attached weather-resistant barrier, Ms. Couturier said. Savings estimates range between 15 and $56 \%$ across the United States, with higher savings in colder regions.

Ms. Couturier said the market adoption of fully adhered weather barriers is challenged by material costs, a lack of appreciation for its protection against weather, and changes in installation practices. The material cost of a fully adhered sheet membrane is greater than the cost of traditional construction practices. However, effective communication of the significant ROI should ameliorate such concerns, she said. Improved airtightness and energy efficiency are appreciable factors; and a fully adhered barrier is more durable during construction so that there is less need for rework, she said. Further value lies in the product's weather resistance, but 
consumers are not familiar with the full robustness of these benefits. By eliminating lateral movement of air and water behind the membrane, it improves durability and reduces the risk of moisture damage. Execution is another challenge: since different installation methods are required, pre-job training must be provided. Fortunately this training takes only a few hours, she said.

Ms. Couturier closed with an optimistic assessment of the current market landscape and prospects for continued adoption of this technology. Fully-adhered vapor-permeable sheets are commercially available; they have been marketed primarily for multi-family and light commercial buildings for 2 years. The products are nationally available via traditional lumberyard, waterproofing, and roofing distributors. Favorable market drivers are promoting adoption, including more stringent code requirements, demand for energy efficiency, and a need for higher resistance to moisture-related damage that can result in litigation. Ms. Couturier said the reception by the building and architectural communities has been positive, with fully adhered products typically becoming the preferred solution following successful projects. Adoption and penetration is following a pattern typical for new building materials.

MARCY TYLER, TREMCO, INC. “AIR BARRIER TECHNOLOGY WITH EXTREME PERFORMANCE IN EXTREME TEMPERATURES”

Ms. Tyler's presentation provided an overview of the building envelope membrane ExoAir111, a next-generation air and vapor barrier technology. She outlined the following key features:

- Product stability at temperature extremes from 20 to $240^{\circ} \mathrm{F}$ ( -7 to $115^{\circ} \mathrm{C}$ )

- Primerless adhesion

- Uniform thickness

- Ultraviolet light resistance

- Reduced material weight

- Assembly evaluated

- Connectivity tested

- UL certification for National Fire Protection Association 285

- Reduces construction delays and the need for multiple products

- Accelerates construction schedules and reduces labor costs

- Provides consistent coverage

- Minimizes installer fatigue and may increase their productivity

- Proven assembly performance of connectivity for air leakage, water penetration, and fire resistance 
Ms. Tyler said $460,000 \mathrm{ft}^{2}$ of the barrier has been sold to date. Table displays a list of barriers to its market penetration next to relevant features that address them.

Table 2: Barriers to ExoAir 111 market adoption

\begin{tabular}{|l|l|}
\hline Barrier & ExoAir 111 \\
\hline Priming & Is primerless \\
\hline Temperature & Can handle temperature extremes \\
\hline Compatibility, adhesion, thickness & Has been evaluated for compatibility and adhesion \\
\hline Connectivity & Has been assembly evaluated for connectivity \\
\hline Ultraviolet resistance & Has been evaluated for ultraviolet resistance \\
\hline Fire resistance & Has been evaluated for fire resistance \\
\hline
\end{tabular}


Tables 2-5 summarize the findings from the relevant breakout sessions with regard to barriers to adoption, potential means of overcoming barriers, general highlights, and any outstanding insights.

NEW ENVELOPE TECHNOLOGIES

Table 2: New envelope technologies_-Moderator highlights

\begin{tabular}{|c|c|c|c|c|}
\hline Technologies & $\begin{array}{c}\text { Modified } \\
\text { atmosphere } \\
\text { insulation }\end{array}$ & $\begin{array}{c}\text { Polyiso- } \\
\text { encapsulated MAI } \\
\text { panels }\end{array}$ & AirFlow panels & $\begin{array}{l}\text { Air barrier } \\
\text { technologies }\end{array}$ \\
\hline Barriers & $\begin{array}{l}\text { Cost } \\
\text { Volume production } \\
\text { Fragility } \\
\text { Continuity } \\
\text { Workforce training } \\
\text { Long-term } \\
\quad \text { performance }\end{array}$ & $\begin{array}{l}\text { Cost } \\
\text { Resistance to new } \\
\text { products } \\
\text { Need to maximize } \\
\text { MAI in a typical } \\
\text { board } \\
\text { Commercial } \\
\text { production } \\
\text { Need for further } \\
\text { technology } \\
\text { development } \\
\text { (cutting, } \\
\text { positioning, failure } \\
\text { indication) }\end{array}$ & $\begin{array}{l}\text { Fear of } \\
\text { decentralization } \\
\text { Hybrid nature- } \\
\quad \text { between } \\
\text { HVAC and } \\
\text { envelope } \\
\text { Risk aversion } \\
\text { Uncertainty } \\
\text { about cost }\end{array}$ & $\begin{array}{l}\text { Codes } \\
\text { Conservative } \\
\text { nature of } \\
\text { industry }\end{array}$ \\
\hline $\begin{array}{l}\text { Potential } \\
\text { solutions }\end{array}$ & \multicolumn{4}{|c|}{$\begin{array}{l}\text { - } \text { Change manufacturing structure } \\
\text { - } \text { Polyiso-encapsulated MAI panels } \\
\text { - Handling risk aversion, through incentives or code requirements } \\
\text { - Bridging the HVAC and building envelope areas } \\
\text { - More research on durability }\end{array}$} \\
\hline Highlights & R-value/inch of 36 & $\begin{array}{l}\text { R-value/inch of } 12 \\
\text { Commercialization } \\
\text { on the horizon } \\
\text { Durable MAI }\end{array}$ & $\begin{array}{l}\text { Controls moisture } \\
\text { and pollutants }\end{array}$ & $\begin{array}{l}\text { Improve } \\
\text { performance of } \\
\text { existing air } \\
\text { barriers }\end{array}$ \\
\hline Aha moment & $\begin{array}{l}\text { Significant cost } \\
\text { reduction }\end{array}$ & & $\begin{array}{l}\text { Significant energy } \\
\text { savings: } 25-50 \%\end{array}$ & \\
\hline
\end{tabular}


AIR BARRIERS

Table 3: Air barriers_-Moderator highlights

\begin{tabular}{|c|c|c|c|}
\hline Technologies & $\begin{array}{c}\text { Sprayable flashing } \\
\text { technology }\end{array}$ & $\begin{array}{c}\text { Fully adhered } \\
\text { weather barrier }\end{array}$ & $\begin{array}{c}\text { Air barriers with extreme } \\
\text { performance in extreme } \\
\text { temperature }\end{array}$ \\
\hline Barriers & $\begin{array}{l}\text { Workforce training } \\
\text { Complexity of system } \\
\text { Ensuring installation quality } \\
\text { (e.g., overspraying, } \\
\text { uncertainty about } \\
\text { sufficiency) }\end{array}$ & $\begin{array}{l}\text { Cost } \\
\text { Installer training } \\
\text { Resistance to new } \\
\quad \text { products }\end{array}$ & $\begin{array}{l}\text { Cost } \\
\text { Risk aversion with regard to } \\
\quad \text { thickness issue }\end{array}$ \\
\hline $\begin{array}{l}\text { Potential } \\
\text { solutions }\end{array}$ & \multicolumn{3}{|c|}{$\begin{array}{l}\text { - Online value calculator } \\
\text { - Training videos in multiple languages } \\
\text { - } \text { Education for architecture, contractors, and other parties } \\
\text { - Better understanding of what works and where }\end{array}$} \\
\hline Highlights & Fast and easy to apply & $\begin{array}{l}\text { Significant energy } \\
\text { savings with } \\
\text { tighter air } \\
\text { barriers, ranging } \\
\text { from } 15-40 \%\end{array}$ & $\begin{array}{l}\text { Proven performance at } 4 \text { mil, } \\
\text { produced at } 20 \text { mil to ensure } \\
\text { long-term performance } \\
\text { Temperature range of product, } \\
\text { covering all applications }\end{array}$ \\
\hline
\end{tabular}

WINDOWS AND SHADING

Table 1: Windows and shading: Moderator highlights

\begin{tabular}{|l|l|l|l|}
\hline Technologies & \multicolumn{1}{|c|}{ Alcoa R5 windows } & $\begin{array}{c}\text { SageGlass } \\
\text { electrochromic } \\
\text { glazing }\end{array}$ & $\begin{array}{c}\text { AERC fenestration } \\
\text { attachments ratings regime }\end{array}$ \\
\hline Barriers & $\begin{array}{l}\text { Code-minimum culture } \\
\text { Using proven technologies } \\
\text { Complexity of windows } \\
\text { Project dependence }\end{array}$ & $\begin{array}{l}\text { ROI calculations } \\
\text { miss key impacts } \\
\text { Human factors not } \\
\text { Fell understood } \\
\text { Economies of scale } \\
\text { Conservative/cost- } \\
\text { friven } \\
\text { construction } \\
\text { awars beyond energy }\end{array}$ & $\begin{array}{l}\text { Communicating information } \\
\text { (marketing and data) } \\
\text { effectively to different } \\
\text { audiences }\end{array}$ \\
\hline $\begin{array}{l}\text { Potential } \\
\text { solutions }\end{array}$ & $\begin{array}{l}\text { Better research, understanding, and communication of human factors } \\
\text { More holistic "balanced scorecard" for calculating true ROI }\end{array}$ \\
\hline Highlights & $\begin{array}{l}\text { Mighly insulating, cost- } \\
\text { effective, and AW } \\
\text { (architectural window) rated }\end{array}$ & $\begin{array}{l}\text { With lighting } \\
\text { controls, a net-zero } \\
\text { energy solution }\end{array}$ & $\begin{array}{l}\text { Mass adoption of commercial } \\
\text { attachments yields energy } \\
\text { savings of 54\% over base }\end{array}$ \\
\hline
\end{tabular}


ENVELOPE RETROFIT APPLICATIONS

Table 2: Envelope retrofit applications-Moderator highlights

\begin{tabular}{|l|c|c|c|}
\hline Technologies & $\begin{array}{c}\text { EnerLogic low-e window } \\
\text { film }\end{array}$ & $\begin{array}{c}\text { Carlisle } \\
\text { Construction roof } \\
\text { tie-Ins }\end{array}$ & $\begin{array}{c}\text { Bayer packaged masonry } \\
\text { wall retrofit solutions }\end{array}$ \\
\hline Barriers & $\begin{array}{l}\text { Clients do not believe } \\
\text { projected savings } \\
\text { More real-world evaluations } \\
\text { needed }\end{array}$ & $\begin{array}{c}\text { Helping clients } \\
\text { choose the best } \\
\text { possible solution } \\
\text { Communicating } \\
\text { long-term value }\end{array}$ & $\begin{array}{l}\text { Envelope retrofits carry high } \\
\text { up-front costs and long } \\
\text { payback periods } \\
\text { Constructability/practicality of } \\
\text { construction is important } \\
\text { factor for retrofit decisions }\end{array}$ \\
\hline $\begin{array}{l}\text { Potential } \\
\text { solutions }\end{array}$ & $\begin{array}{c}\text { Conduct more real-world tests, simulations, and mock-ups to demonstrate } \\
\text { feasibility of innovations to customers } \\
\text { Capture, identify, and communicate more holistic ROI information } \\
\text { Better integrate the envelope supply chain-more coordination amongst } \\
\text { trades, suppliers, contractors, and customers for holistic solutions }\end{array}$ \\
\hline Highlights & $\begin{array}{l}\text { Offers year-round savings, } \\
\text { both winter and summer }\end{array}$ & $\begin{array}{l}\text { Building codes are } \\
\text { likely to soon } \\
\text { mandate roof tie- } \\
\text { ins aggressively }\end{array}$ & $\begin{array}{l}\text { Integrated package will reduce } \\
\text { air leakage, improve thermal } \\
\text { performance, and manage } \\
\text { moisture performance and } \\
\text { durability }\end{array}$ \\
\hline \multicolumn{2}{|c|}{} \\
\hline
\end{tabular}


RESIDENTIAL AND COMMERCIAL CROSSCUTTING

MIKE ENNIS, SPRI, “CODE AND GREEN BUILDING DESIGN GUIDE REQUIREMENTS AND THEIR IMPACT ON ENERGY EFFICIENCY”

Since 2006, Mike Ennis has been technical director for SPRI, the association representing singleply roofing manufacturers and component suppliers. Previously, he worked for The Dow Chemical Company for 30 years. He was the North American application technology leader for commercial products in Dow's Building Solutions business, for which he led the development of new products and applications. Mr. Ennis has 40 years of building and construction experience, is a registered roof consultant with RCI, and is board chairman of the Cool Roof Rating Council. $\mathrm{He}$ is the immediate past chair and a board director of the Roofing Industry Committee on Weather Issues. Mr. Ennis is a member of ASHRAE and serves on ASTM committees including D8 Roofing and Waterproofing, E5 Fire Standards, and E60 Sustainability.

He began his presentation by discussing code and green building design requirements and their impact on energy efficiency. Highlighting the patchwork of such regimes, he gave brief overviews of national energy codes (IECC, ASHRAE 90.1), state energy codes (specifically California Title 24), green codes (ASHRAE 189.1, IGCC) and green guides (LEED, GBI, Energy Star). The landscape can be overwhelming from a compliance perspective, he said.

Before any code can come into existence, extensive research must be conducted. To illustrate, Mr. Ennis mentioned cool roof studies. Hundreds of such studies have been conducted assessing energy impact, impact on urban islands, materials performance, and building occupant comfort. These studies are geographically diverse, as well, covering the United States, Japan, Europe, Asia, the Middle East, China, and India, among others. Mexican researchers also have modeled significant cooling energy savings from cool roofs. ORNL's Envelope Systems Research Apparatus was used for evaluations in an SPRI/ORNL/DOE cool roof experimental design.

After research is conducted, the process of code development begins, he said. Such endeavors typically feature large auditoriums with stakeholders from numerous relevant groups, all with their own opinions, concerns, and fields of expertise. Much like any legislative process, Mr. Ennis said, code development can be compared to sausage making. This process iterates through all of the regulatory bodies and regimes. Different entities have different priorities and dictate different measurements. Trying to promulgate new benchmarks requires targeting to different political levels for different users and needs. 


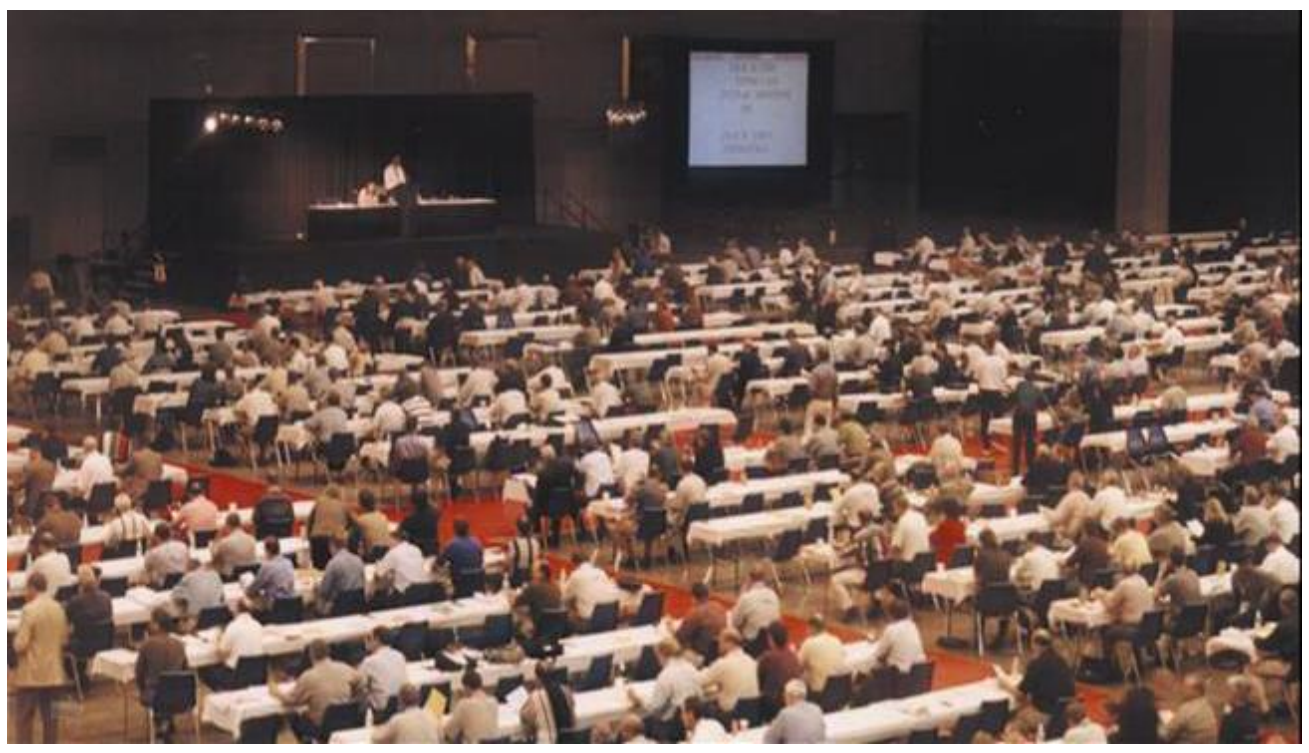

Figure 13: ICC Code development process.

Mr. Ennis shared some insights on leveraging codes to effect change: Conduct rigorous and thorough research in advance of any new proposal. Know your audience before pushing innovation. Translate selling points and benefits into relatable language. He mentioned that many energy codes have both proscriptive and performance paths. If you can demonstrate that a proposal is equivalent to an existing code, then you can see it realized via the performance path. An example is showing the level of insulation needed to equal the performance of a reflective roof. Tying all of these points together, he mentioned that research conducted at ORNL led to the creation of a calculator that determines the performance equivalent point between insulation and reflective roofing. 


\section{CLOSING REMARKS}

DOUG BROOKMAN, “REPORT OUT FROM RESIDENTIAL SESSIONS”

Mr. Brookman began by discussing the Building America Roadmap and the arrangement of variables that will lead to the most useful version of that framework. Navigating and addressing codes and standards remains a critical point, he said. The Roadmap has articulated a goal of proper assessment of risk, yet there remain difficulties in establishing the exact risk factors. Technical challenges exist, but implementation considerations are far greater. Much potential growth depends on building envelope technology implemented at installation, he said. The industry should seek to clarify how much is not known about how much is needed. Numerous data gaps exist. As ever, current data and measurements are lacking. Innovation is driven by additional standards implemented properly and sufficiently by proper bodies with proper vetting. The interplay between elements of the building envelope is unknown, as well-how these systems react, how the features of a system interact, and how they change over time are all relative unknowns at present. Front-end tests are fine, but what about 5 years later, or during a waterinfiltration event? The industry needs better information and more robust systems and protocols to capture, analyze, and disseminate that information.

\section{AMY JIRON}

Ms. Jiron said this workshop is the beginning of discussions of the building envelope in the commercial sector, including opening the doors between end-users, providers, and developers. She asked for information, perspectives, and general outreach via email to her directly and to other DOE staff. Success is possible through collaboration between partners, networks, and activities, she said. Large-scale success demands strategic thinking and strategically guided messages. Currently complicated, these communications must exhibit greater simplicity, distilling the complex into the simple.

\section{ERIC WERLING}

Mr. Werling stated that everyone agrees that the perceived risk of tackling the issues in the roadmap is high; but overall, no major structural changes are needed. Huge challenges remain in developing a framework covering all research and development priorities; they include the need to address codes and standards reform and improvement. To cover everything that needs to be covered in the requisite level of detail, follow-up is necessary. Therefore, participants will be asked for additional feedback and input as questions arise. Next year, teams will be formed to tackle each of the major challenges identified in the roadmap. 
The 2015 Building Envelope Stakeholder Workshop featured a large number of compelling presentations and insightful discussions. Contributions from a variety of participants permitted valuable feedback. It will in turn be used to guide several critical initiatives, including the Building America Roadmap and ORNL's ongoing efforts to foster the adoption of more energyefficient envelope technologies in the residential and commercial sectors. Lively discussions centered specifically on barriers to the adoption of advanced technologies and how relevant stakeholders may best collaborate to meet them.

A common theme was information: identifying which information needs to be collected, improving the collection processes, and disseminating information to those who might benefit from it effectively. Whether in the commercial or the residential world, the need for information is the true challenge, and the building industry is better positioned to address it as a result of this workshop.

All who attended the workshop and who read this summary are encouraged to remain engaged and share their input. It is your contributions that will continue blazing the path toward nearzero-energy buildings; and given the events detailed in this workshop, there is great reason to be optimistic that that goal can be achieved. 


\section{Envelope Stakeholder Workshop Participants}

$$
\mathbf{N}=\mathbf{1 0 0}
$$

Rahul Athalye

Pacific Northwest National Laboratory

Ion-Horatiu Barbulescu

Alcoa BCS - Kawneer Company, Inc.

David Baur

WR Grace

Paul Bertram

Kingspan Insulated Metal Panels

Mahabir Bhandari

Oak Ridge National Laboratory

John Breshears

Architectural Applications

Douglas Brookman

Public Solutions, Inc.

Heather Buckberry

Oak Ridge National Laboratory

Adam Cavender

Knox County Schools

Michelle Coates

Consortium for Building Energy Innovation (CBEI)/ Booz Allen Hamilton
Johanna Coetzee

Design Innovation

Pam Cole

Pacific Northwest National Laboratory

Jeromy Cotten

Tennessee Valley Authority

Marysusan Couturier

WR Grace

Jay Crandell

ARES Consulting

John Crowley

Rollease/AERC

Laverne Dalgleish

Air Barrier Association of America

Steven DeBusk

Eastman Chemical

Samuel DeLay

Tennessee Valley Authority

Andre Desjarlais

Oak Ridge National Laboratory

Richard Duncan

Spray Polyurethane Foam Alliance 
Elizabeth Eason

Elizabeth Eason Architecture, llc

Ken Eckert

Metropolitan Knoxville Airport Authority

Jacene England

StudioFourDesign

Mike Ennis

SPRI, Inc.

David Erne

Booz Allen Hamilton

Katherine Faber

The Dow Chemical Company

Scott Falvey

Design Innovation

Michael Fenner

Target

Rick Fink

Target

Diana Fisler

Johns Manville

Zane Foraker

Knox County Schools

Mike Ford

Garland Company (Knoxville BOMA

President)

Charlotte Franchuk

Oak Ridge National Laboratory
Andrew Frye

Tennessee Valley Authority

Gary Gardner

Bayer Material Science

Stanley Gatland II

CertainTeed Corporation

Samuel Glass

USDA Forest Products Laboratory

Chris Gray

Southern Company

Johney Green

Oak Ridge National Laboratory

Dianne Griffiths

Steven Winter Associates, Inc.

Anthony Grisolia

IBACOS Inc

Tyler Grubbs

Sentech, Inc.

Bahman Habibzadeh

Department of Energy

Kerry Haglund

Efficient Windows Collaborative

John Hannum

Vidaris, Inc.

Gary Hardin

Icynene 
John Hillenbrand
Owens Corning

Jim Hinton

Cope Architecture

Jason Hoerter

NCFI Polyurethanes

Nicholas Holt

Skidmore, Owings and Merrill (SOM)

Bill Hooper

Alcoa Building and Construction Systems

Bryce Hudey

Oak Ridge National Laboratory

Patrick Huelman

University of Minnesota

Diana Hun

Oak Ridge National Laboratory

Eric Jackson

Quanex

Roderick Jackson

Oak Ridge National Laboratory

Amy Jiron

Department of Energy

Achilles Karagiozis

Owens Corning

Manfred Kehrer

Oak Ridge National Laboratory
Gannate Khowailed

Sentech, Inc.

Sneh Kumar

Alcoa/Kawneer

Jim Lambach

Bayer Material Science

Melissa Lapsa

Oak Ridge National Laboratory

John Letts

Firestone

Leon Levitt

$3 \mathrm{M}$

Dolynn Loy

Oak Ridge National Laboratory

Joseph Lstiburek

Building Science Corporation

Peter Ludman

Cope Associates, Inc.

Bill Miller

Oak Ridge National Laboratory

Terry Morton

BARBERMcMURRY architects

Jean-Philippe Ndobo-Epoy

Certainteed

Leslie Nicholls

Energetics Incorporated 
Randy Nicklas

Icynene, Inc.

Simon Pallin

Oak Ridge National Laboratory

Dave Pennington

PROSOCO

Cecil Peters

Oak Ridge National Laboratory

Jim Petersen

Lennar Ventures

Ben Polichnowski

Escore Program with TVA

Shawn Prestegaard

$3 \mathrm{M}$

Sam Raskhin

Department of Energy

Stacey Rothgeb

National Renewable Energy Laboratory

Helen Sanders

SAGE Electrochromics, Inc.

Tom Schneider

Building Envelope Innovations

Fred Schubert

NCI Building Systems

Christopher James Schumacher

Building Science Labs
Som Shrestha

Oak Ridge National Laboratory

Karen Sikes

Sentech, Inc.

Clarence Tolbert

NCFI Polyurethanes

Karen Triplett

Oak Ridge National Laboratory

Craig Tyler

Carlisle Construction Materials

Marcy Tyler

Tremco, Inc.

Stefan Wankerl

US Cellular

Eric Werling

Department of Energy

Theresa Weston

DuPont

Jeremy Williams

Department of Energy

Teresa Williams

Oak Ridge National Laboratory

Jon Winkler

National Renewable Energy Laboratory

Amy Wylie

CBEI/Bayer MaterialScience 
Shanzhong Yuan

Home Innovation Research Labs 